\title{
Advances in Systemic Trauma Theory: Traumatogenic Dynamics and Consequences of Backlash as a Multi-Systemic Trauma on Iraqi Refugee Muslim Adolescents*
}

\author{
Ibrahim A. Kira1, Linda Lewandowski², Lisa Chiodo² ${ }^{2}$, Arwa Ibrahim ${ }^{3}$ \\ ${ }^{1}$ Center for Cumulative Trauma Studies, Stone Mountain, USA \\ ${ }^{2}$ University of Massachusetts, Amherst, USA \\ ${ }^{3}$ Drexel University, Philadelphia, USA \\ Email: kiraaref@aol.com
}

Received 20 February 2014; revised 21 March 2014; accepted 12 April 2014

Copyright (C) 2014 by authors and Scientific Research Publishing Inc.

This work is licensed under the Creative Commons Attribution International License (CC BY). http://creativecommons.org/licenses/by/4.0/

(c) (i) Open Access

\begin{abstract}
Development in adolescence puts youth in direct contact with social systems, thereby increasing exposure to systemic traumas. The present article aims to advance systemic trauma theory as part of a new development-based trauma framework (DBTF). It examines discrimination and backlash against Muslim Americans as an example of a multi-systemic trauma to investigate its mental health ramifications. Measures of cumulative trauma, backlash trauma, post-traumatic stress disorder, Adolescent Psychopathy Scales (APS), annihilation anxiety, and cumulative trauma disorders were administered to 224 Iraqi refugee adolescents. Partial correlation and hierarchical multiple regression results indicated that backlash was associated with the most negative mental health outcomes as compared to other trauma type seven after controlling for overall life trauma. The validity and utility of the proposed theoretical framework and the clinical implications of negative mental health effects of multi-systemic traumas on refugee adolescents were discussed.
\end{abstract}

\section{Keywords}

Systemic Traumas, Multi-Systemic Traumas, Developmental-Based Trauma Framework (DBTF), Muslim American, Arab Americans, Iraq Refugees, Backlash Trauma

\footnotetext{
${ }^{*}$ The results of this study were initially presented in the American Psychological Association Annual Convention, at Hawaii, on August 2013, as part of a symposium on Systemic Trauma.

How to cite this paper: Kira, I. A. et al. (2014). Advances in Systemic Trauma Theory: Traumatogenic Dynamics and Consequences of Backlash as a Multi-Systemic Trauma on Iraqi Refugee Muslim Adolescents. Psychology, 5, 389-412. 


\section{Introduction}

One of the potential problems with the current status of stress and trauma theory is its individualistic bias that tends to ignore the traumatogenic dynamics of systemic intergroup conflict and of social structural and institutional traumas. Individualistic bias may contribute to a lack of clear understanding of this relationship between an individual's mental health, socio-political movements, and social pathology. Individualistic bias has limited current efforts to understand and address group violence, political uprisings and social pathology. Dominant stress and trauma theory approaches are additionally problematic in their focus on past traumatic events, and common disregard for present and continuous traumas that may not cease in one's lifespan (e.g. discrimination, slavery, poverty, and cast systems). Substantial theoretical, empirical, and clinical work tends to examine trauma as it is perpetrated by an individual targeting another individual (van der Kolk, Weisaeth, \& van der Hart, 1996), while systemic traumas perpetrated by groups, or institutions against their and other groups members, did not receive much attention, until recently.

An individual cannot exist alone. He/she is impeded within dynamic and fluid systems of familial, social and ecological forces. The power and centrality of systemic traumatogenic and salutogenic dynamics configure an individual's emotional, cognitive and behavioral systems (e.g., Speed, 1999). Individual switches, in the developmental path, from attachment to parents to attachment to friends, other significant others, and then to the developing social networks and interdependent interpersonal and social systems. The new technologies enhanced the connections and communication between such networks. While attachment, individuation and identity are important stages of development, individuation and identity development takes shape within such networks of social and ecological systems. Systemic, indirect or secondary traumas are major class of events that shape individual's development and structure his/her suffering and or growth in the interdependence developmental path (e.g., Figley, 1995; Kira, 2004; Klarić, Kvesić, Mandić, Petrov, \& Frančišković, 2013). Research has linked societal non-targeted macro-systemic adversities (e.g., recessions and economic downturns) to negative mental health outcomes (McLaughlin et al., 2011) and increases in violence, aggression and hostility (e.g., Barlett \& Anderson, 2013; Catalano, Snowden, Shumway, \& Kessell, 2007; Fischer, Greitemeyer, \& Frey, 2008; Rosenfeld, 2009). However, research on the targeted and micro-systems' traumatogenic dynamics (e.g., backlash against minorities, genocide, racism, discrimination, holocaust) on individuals and groups is still in its inception and lacks comprehensive theoretical formulation that strengthens its advance and explains its dynamics. Developing plausible theoretical framework will generate more testable hypotheses and enrich our knowledge of these serious traumas that are in play world-wide. The dynamics of such systemic traumas (ST) are poorly understood and their mental health effects are understudied. Further, there is a need for new testable paradigms that integrate individual and systemic traumas and explicate their differential and joint cumulative dynamics in real time. We aim to develop an organizing testable framework that helps us understand such dynamics.

A relatively recent developmentally-based bi-dimensional trauma framework (DBTF) integrated the theories of stress and traumatic stress and its main paradigms including systemic and non-systemic traumas (Kira, 2001, 2004, 2010; Kira et al., 2008a, 2011; Kira, Fawzi, \& Fawzi, 2012d; Kira et al., 2013; Kira, Omidy, \& Ashby, in Press). DBTF framework is based on the assumption that adversities either impede or enhance individual development across the life span. Enhancing individual development is one of the main foci of clinical and psychological sciences. Another assumption is that stress and trauma can moderate (facilitate or impede) development (Aldwin, 1994). Another assumption related to DBTF is the importance of integrating an individual's developmental experiences and their cumulative dynamics, as focusing on single traumas can be misleading. Another assumption is that globalization changed the dynamics of individual development and placed technological capacities and mass communication in the center of an individual's experience and trauma theory and created new individual's virtual identities.

DBTF framework defines traumatization as "a process that can be triggered by stressors with different levels of intensities that can range from chronic hassles to severe traumatic stressors, such as Hiroshima bombing, holocaust, and oppression and have potential to trigger post-trauma spectrum disorders, and/or yield post-trauma spectrum developmental competencies and growth” (Kira, 2001; Kira, Ashby, Lewandowski et al., 2013: p. 397). Traumatization, according to this framework, is a potential threat to and/or a challenge to the developmental assets, resources and capacities that the individual acquired and that give him/her agentic ability to deal with such challenges. This threat can be uni- or multi-dimensional and include the threats to the survival of his/her grow- 
ing body, his/her secure attachment, his/her growing personal and collective identities, his achieved role identity, his/her interdependence capacities within the social networks and allegiances and belonging capacities and competencies. These challenges may facilitate (or delay) the emergence of more developmental assets/capacities or harm his/her acquired ones. Traumatization takes different manifestations and trajectories depending on their sources. For example entrapment, uprootedness/ estrangement, oppression, betrayal, and identity annihilation threats are different valid scenarios, among other potential trajectories of traumatization.

In DBTF framework, the individual's developmental assets facilitate his/her best use of other different, internal, interpersonal, cultural and environmental resources to respond to adversities. Developmental assets include (but not limited to) will to survive and/or thrive, secure attachment, the developed/ developing personal autonomy and feeling of and having an executive control (personal identity), role identity and related personal achievements and identity related personal and collective self-efficacy and self-esteem, his/her developing values and belief systems, his social competence, psychosocial maturity, and his ability to interdepend being integrated part of social networks that may include seeking, providing and receiving social and material support. Such developmental assets include his/her able body's functioning organs that develop across life span together with his/her brain, related neurological and physiological systems as well as associated cognitive and emotional processing and behavior. Developmental assets facilitate the development and use of internal, environmental and cultural resources. Developmental assets are fluid as they emerge, grow and, or decline with challenges and across the natural course of life span and development (c.f., Baltes, 1987). Such developmental assets, when areintact, help the individual to optimally utilize the available internal and environmental resources relevant to specific challenges and adversities (for review of different resource theories see Hobfoll, 2002). Developmental assets are, as such, prerequisites to optimal resources utilization process. The interplay between genetics, stresssors, trauma types, its cumulative dynamics and resulted epigenetics unfolds over time to produce varieties and patterns of individual's developmental assets and/or losses. Individual's resiliency, distress tolerance and ability to cope with adversities are determined by the status of his/her developmental assets. The importance of collective interdependence developmental assets is especially evident in the case of systemic and multi-systemic traumas. The individual is an intricate part of such systems that he/she belongs to and is part of his/her emerging developmental assets that are crucial to coping. Systemic traumas may deprive the individual of important developmental assets and deactivate this important part of his/her social development.

The first dimension of DBTF is horizontal (vs. vertical) and development-focused and includes attachment (for example attachment disruptions; Bowlby, 1973), individuation (personal and social identities; Erikson, 1968), interdependence (secondary andtertiary; Figley, 1995; Kira, 2004), and self-actualization (or role identity) (Maslow, 1987) related traumas. Its vertical or severity dimension identifies four types of traumas: type I (single episode), type II (repeated similar episodes in the past), type III (chronic traumatic and non-traumatic stress), and type IV (cumulative trauma across life) (e.g., Kira, Fawzi, \& Fawzi, 2012d; Kira, 2004; Terr, 1991). The new paradigm contributes to moving the field forward out of the limited psychiatric perimeter of the DSM with its emphasis on single individual traumas (criterion 1 for PTSD) to the wider operating poly-traumatization and cumulative trauma model. Kira et al., 2008, Kira, Fawzi, \& Fawzi, 2013, found that none of the traumatic events or types made an independent contribution to the prediction of PTSD, depression or anxiety, once cumulative trauma was considered. Similar results were found in poly-victimization research (Cyr, Clément, \& Chamberland, 2103).

The authors regard this trauma typology as a heuristic device for assessment, analysis, and interpretation of data collected in this study. The interdependence dynamics, in this trauma typology, highlight the effects of systemic and multi-systemic trauma (the focus of current study). In this paper, we will further develop the interdependence element of this typology as it may advance our understanding of systemic traumas. We will utilize the developed framework in an empirical study to test its utility and validity through investigating some of its assumptions.

Systematic trauma (ST) is a type III trauma defined as a stressor caused by one social system or group upon an individual member(s) of the same and/or different systems or groups. Multi-systemic trauma (MST) implies that more than one social system or institution perpetrated or contributed to such trauma, which may make it more intense. ST fluctuates in its severity and consists of chronic "quasi-traumatic" stressors (e.g. micro-aggression such as insults or bullying) as well as severe traumatic stress (e.g., macro-aggressions such as hate crimes). Events of macro-aggression increase the targeted individual's sensitivity to micro-aggressions. ST is socially originated from group affiliation and collective identity dynamics. Further, ST tends to proliferate followed by 
subsequent cascades of related traumas (e.g., job loss, vanishing opportunities, and bullying; Kira et al., 2013; Pearlin, Aneshensel, \& LeBlanc, 1997). Depending on the implicit or explicit goals of perpetration, ST can range in its severity from systemic betrayal (e.g., discrimination, stereotyping, loss of support) to domination and/or subjugation (e.g., oppression, occupation, slavery and caste systems), to reactive global oppression in intergroup conflict (e.g., backlash against Japanese Americans after Pearl Harbor and against Muslims and Arab Americans after September 11), to annihilation and elimination attempts or threats (e.g., holocaust and genocide).

Backlash trauma (BT) against minorities, the empirical focus of this paper, is one example on the continuum of such multi-systemic traumas. BT is defined as "an intensified reactive discrimination or micro and macro aggressions toward a minority group as a response to an act of aggression by individuals or sub-groups perceived to be associated with that group" (Kira et al., 2010). The goal of this article is to explore the theoretical basis of this line of traumas, its dynamics, and examine empirically the mental health impact of one of its variants: the backlash trauma (BT) against Muslims and Arab Americans after the events of September 11, 2001. Investigating the mental health impact of BT on Muslim Iraqi refugee adolescents provides a case example that may apply to other victims of such traumas.

\subsection{The Theoretical Basis of Systemic Traumas: Its Sources and Dynamics}

1) Sources of Systemic Traumas:

There are at least four potential sources of systemic traumatic processes that sometimes overlap. They involve threats to a collective (social) identity and include: institutional-based, intergroup conflict based, and social structural violence-based and globalization-based traumas. We will discuss each of these sources before discussing their dynamics.

a) Institutions-Based Trauma:

Abandonment and neglect is a fundamental betrayal of trust in primary relationships of the child. Emerging trauma literature started to expand betrayal theory to adults as practiced by institutions, cultures, and communities that contribute to psychological and physical health and to emerging social movements (Freyd, DePrince, \& Gleaves, 2007; Platt, Barton, \& Freyd, 2009). Institutions such as schools and universities, religious institutions, the military, work environments, hospitals, jails and prisons; agencies such as police, foster care, immigration, federal assistance, disaster management, and the media; motivated by their corporate cultures, can have a positive or negative role for supporting, ignoring, betraying and/or directly targeting and traumatizing victims (Kira, et al., 2013).

b) Inter-Group Conflict Based Traumas

Inter group conflicts can involve war, oppression, torture, terrorism and forced refuge (Sidanius \& Pratto, 1999; Tajfel \& Turner, 1979). Chronic racism, sexism, discrimination, homophobia and genocide are tools associated with intergroup aggressions that sometimes are initiated to dominate, subjugate, denigrate, exclude or annihilate the targeted group. Such traumatic conditions can fluctuate and may escalate after an event in an overall backlash against the targeted group(s), setting off annihilation anxieties.

c) Social Structural Violence-based Traumas

Influential majorities, or dominant social structures, with their chronic control can accept or set extreme differential boundaries between social classes and categories that can be transmitted cross-generationally (Smith, Pettigrew, Pippin, \& Bialosiewicz, 2012). Such powers can be perceived by the impacted individual or the group as sources of traumatic threats of injustice that may limit the chances of survival, development and advancement. Such conditions and perceptions leave the individual victim feeling helpless, lacking self-efficacy, with lower self-esteem and feelings of betrayal by dominant affiliated structures that were assumed to protect and enact fairness and inclusion. Extreme gender discrimination (Kira et al., 2012c; Kira, Smith, Lewandowski, \& Templin, 2010a), extreme poverty and relative deprivation (Cassiman, 2005; Smith, Pettigrew, Pippin, \& Bialosiewicz, 2012), and caste systems (e.g., Berreman, 1972), are examples of chronic traumatic stress processes that set off feelings of betrayal and annihilation or subjugation anxieties. Some demographics (for example SES and gender) have been used, in research, as proxies to structural inequalities that represent social structural violence (e.g. gender discrimination and poverty).

While powerful dominant groups or institutions may commit direct traumatic violence (by e.g., oppression, persecution, discriminations and/or torture) they may indirectly exercise their hegemonic violence over minori- 
ties and castes. They shape, enforce, reproduce and legitimize their prejudices and discriminations by manipulating the grid of individuals' perception and establishing a perceptual matrix, and cultures that influences and perpetuates their systems of thinking, severe inequalities, prejudices, dominant behavior and values, that make them unquestionable and acceptable by even the victimized groups. This involves the creation of a symbolic culture through education, religion, social value systems, media, and recent tools of globalization such as the internet which serve as tools for perpetuating, reproducing, rationalizing and legitimizing their unfair dominance. Symbolic or indirect systemic violence consists of institutions enforcing unequal standards of oppression and injustice upon members of a particular group or minority (for example in the cases of slavery, cast systems, extreme gender and other discriminations, dictatorships). The debasing of such minorities became socially acceptable and as such concealed the actual dominant systems of power operations (Bourdieu \& Passeron, 1990).

d) Globalization-Based Systemic Traumas

The emergence of globalization generated a cascade of rapid changes of macro and micro social and socio-economic stressors precipitating global interdependence dynamics and expanding inequalities (Daly, Duncan, Kaplan, \& Lynch, 1998). The real-time virtual transmission of relevant and important news for individuals and groups has its gradient effects that range from uplifting to traumatic (Huesmann, Dubow, Boxer, Souweidane, \& Ginges, 2012; Kira et al., 2008b; Silver et al., 2013). Globalization re-structured the systemic negative and positive influences. The Great Recession, the massive economic meltdown, and global climate change with devastating earthquakes and storms have increased the direct and indirect (secondary) and virtual systemic influences. For many, such virtual traumatic events proliferate with increased suicides, family violence, stress-related diseases, and mental disorders (Pearlin, Aneshensel, \& Leblanc, 1997). The Pearl Harbor attacks, Hiroshima atomic bombing, and September 11 events are also virtual traumas transmitted through the media. Such events, not only affect those who are directly impacted, but also the listeners/viewers of such events that are relevant and important to their collective or personal identity (Kira et al., 2008b; Silver et al., 2013). Thus, globalization is closely related to identity and interdependence development especially for adolescents and refugees (Carolissen, 2012). Further new virtual or cyber identities have been created by electronic media that can be subject to new identity theft crimes and their potential stress or traumatic effects (e.g., Roberts, Indermaur, \& Spiranovic, 2013). Other globalization-based systemic traumas, such as cyber-bullying (e.g., Bonanno \& Hymel, 2013) are emerging.

Studies have documented the negative effects of viewing the September 11 attacks on Americans' mental health (Silver et al., 2006; Silver et al., 2013; Neria \& Sullivan, 2011). Listening to and watching the news of war in Iraq by Iraqi refugees in the US has been found to be a virtual trauma that was highly predictive of PTSD, complex PTSD, and poor health after controlling for the effects of previous cumulative traumas and demographics (Kira et al., 2008b; Silver et al., 2013).

2) The Dynamics of Systemic Traumas: Systemic traumas entail distinctive dynamics that can include serious chronic and acute threats to the rooted individual's social inclusion and belonging and to his existential identity, personal and collective. Such threats from different systemic trauma can intersect, amplifying each other, triggering linear and non-linear cumulative dynamics that can trigger existential annihilation/ subjugation anxieties and potential post-traumatic trauma spectrum disorders or post-traumatic developmental growth. The followings are some of its observed dynamics:

A) Social exclusion and rejection dynamics

Social networks connote complex sets of relationships between members of social systems at all scales, from interpersonal to international, and from bounded groups (e.g., tribes, families) to social categories (e.g., gender, ethnicity) (e.g., Kadushin, 2012). Social networks and systems are highly dynamic and fluid. Dynamical systems theory posits that such continuous mutual exchanges between such temporal traumatogenic systemic interactions give rise to linear and non-linear relations, loops and dynamics (e.g., Spivey \& Dale, 2006; Beer, 1995). One of such central operating dynamics of systemic traumatization is the mechanisms and outcome of social inclusion/exclusion (Baumeister \& Leary, 1995). Implied threats to collective identity of the individual and related anxieties are additional central mechanisms that range from denigration to subjugation to threats of annihilation and the reactions to such threats.

a) The Importance of Social Inclusion in Systemic Trauma

The individual develops from being dependent and attached to parents, to being an autonomous interdependent agent with emerging feelings of belonging, security and rootedness in different systems and groups (Begen \& Turner-Cobb, 2012). While dependence on a responsible caring adult characterizes the existence of a child, in- 
terdependence defines the status of existence and identity development in adolescence and adulthood. At the core of the concept of interdependence are relationships, connections and networks. Interdependence allows the person to seek, receive, perceive and give social and other material and non-material support from others, as well as exchanging of important and relevant information that help in taking appropriate life decisions. Globalization leads to an ever-increasing interdependence through different direct and indirect social networks of belonging. Direct or explicit social networks include personal, friendship, family, coworkers or neighbors networks, while indirect or implicit social networks include the larger groups (categories) that a person identifies with, for example gender, ethnic, religious and even sport teams fans (e.g., Wann, Waddill, Polk, \& Weaver, 2011; Cornil \& Chandon, 2013). Interdependence is a relationship in which each member or unit of analysis is mutually dependent on the others. What affects one individual or unit in this system, negatively or positively, can affect all the other individuals or units through such systemic, secondary and tertiary dynamics. The concepts of secondary trauma, vicarious trauma, joint and shared trauma, compassion fatigue (e.g., Figley, 1995; Kira, 2004), systemic trauma and related concepts emanate from such salient systemic dynamics.

Belonging and social identity are central aspects of an individual's social meaningful existence. The desire for inclusion and belonging to groups (e.g., institutions and social systems) is a fundamental human motivation and a core human need (Baumeister \& Leary, 1995). Inclusion and general and social connections across many domains (e.g., with friends, intimate partners and even strangers, and nature) typically predict well-being and other positive outcomes (Aron, Aron, \& Smollan, 1992; Leary et al., 2008; Malone, Pillow, \& Osman, 2011; Waugh \& Fredrickson, 2006). Holt-Lunstad, Smith and Layton’s (2010). Meta-analysis concluded that social isolation is as deadly as excessive alcohol consumption and smoking, and is associated with increased mortality and morbidity. Both feeling lonely and being socially isolated were found to raise the mortality risk (Wrzus, Hanel, Wagner, \& Neyer, 2013) and are associated with negative mental and physical health and well-being, while feeling socially connected and having high social capital (social capital may include social networks involvement, social participation, social support, mutual aid and reciprocity) is strong source of resilience, well-being, longevity and positive mental and physical health (e.g., De Silva, McKenzie, Harpham, \& Huttly, 2005; Chu, Saucier, \& Hafner, 2010; Gilbert, 2010; Haber, Cohen, Lucas, \& Baltes, 2007; Murayama, Fujiwara, \& Kawachi, 2012; Nyqvist, Pape, Pellfolk, Forsman, \& Wahlbeck, 2013; Poortinga, 2006; Prati \& Pietrantoni, 2009). Loneliness can make you feel chronically threatened, an emotion that can wear on the immune system (Cacioppo \& Patrick, 2008) and negatively affects physical and mental health.

b) Chronic Social Exclusion/Rejection and Its Consequences

Chronic social exclusion is a basic traumatogenic mechanism in refugees' involuntary up rootedness in excommunication, solitary imprisonment, internment, and in discrimination and backlash against minorities. Ostracism, social rejection and betrayal threaten the primary human needs of belonging, control, self-esteem, and a meaningful existence (Williams, 2009; Freyd, DePrince, \& Gleaves, 2007).

Social exclusion plays a salient role in the health and resilience (e.g., Begen \& Turner-Cobb, 2012). According to the Schmitt \& Branscombe (2002) rejection-identification model, pervasive discrimination an in-group experiencing implies rejection of the group from the broader network in general and from those who have positions of power and status in particular.

There is evidence that the negative effects of exclusion are higher among adolescents (Kloep, 1999) as they experience social identity development. Adolescent rejection by peers is associated with depression, lower self-esteem, poor academic achievement and dropping out of school, suicide (Kim \& Leventhal, 2008), school shootings (Leary, Kowalski, Smith, \& Phillips, 2003), and higher levels of aggression (Reijntjes et al., 2010; for a meta-analysis of the effects of exclusion see Gerber \& Wheeler, 2009).

Rejection, (Baumeister, Twenge, \& Nuss, 2002), and forced uprootedness (Holtz, 1998) can have serious negative effects on cognitive functioning and on physical and mental health. Interpersonal exclusion was found to be associated with internalizing disorders (e.g., depression) (Brendgen, Wanner, Morin, \& Vitaro, 2005; Sandstrom, 2004), externalizing disorders (e.g., conduct disorders) (Laird, Jordan, Dodge, Pettit, \& Bates, 2001), and gang membership (Dishion, Nelson, \&Yasui, 2005). Baumeister, Twenge, \& Nuss (2002) found that social exclusion is associated with a significant reduction in logic and reasoning ability and decrements in intelligent thought (including suppressed IQ and lower Graduate Record Examination test scores) as well as a decline in both speed and accuracy of processing. In a longitudinal study, social rejection during adolescence was linked to changes in the immune system that could result in negative physical health outcomes down the road (Murphy, Slavich, Rohleder, \& Miller, 2012). Targeted rejection was found to trigger inflammatory gene expression in 
adolescents and up-regulate pro-inflammatory signaling molecules, increasing risk for a variety of inflammation-related diseases including depression, obesity, diabetes, cardiovascular disease, and cancer (Murphy, Slavich, Rohleder, \& Miller, 2013).

B) Linear and Non-Linear Cumulative Dynamics

Because most of systemic traumas are especially chronic, their cumulative trauma load is unique and can have serious physical and mental health consequences especially when they interact with or added to other non-systemic stress and traumas. When enough stress and trauma load accumulates, outweighing the protective factors and crossing the threshold of an individuals' distress tolerance, cumulative trauma disorders develop. Different trauma profiles yield different outcome profiles (different profiles of physical and mental health comorbidities). For example, internalizing, externalizing, cumulative trauma disorders or different configurations of co-morbidities may occur.

While a dose-response model (the change in effect caused by differing levels of exposure) describes linear traumatogenic dynamics (e.g., Altshuler, 1981), the cumulative trauma model proposes, additionally, different cumulative non-linear dynamics inherent in the threshold model. This implies a threshold value at which the behavior varies significantly (Kira, Smith et al., 2010; Kira Templin et al., 2006). This model presumes that humans may have breaking points at which they may experience a psychiatric casualty (for example, decompensation or suicide) or criminal activity (for example mass killing), or both. Such non-linear dynamics of cumulative trauma are present in multiply traumatized individuals (Kira, Amer, \& Wrobel, 2014; Kira, Templin, Lewandowski, \& Ashby, 2012).

Such non-linear dynamics are sometimes ignored, though are important in predicting unpredictable individual and group behavior. tolerance (DT) is defined as the ability to persist in goal-directed behavior while experiencing affective distress. The notion of a threshold of tolerating distress (e.g., Zvolensky, Bernstein, \& Vujanovic, 2011), is especially relevant to understanding cumulative trauma dynamics in victims of chronic systemic traumas. Research results indicated that distress tolerance is temporally stable for the individual, with little mean- or individual-level change (e.g., Cummings et al., 2013). Distress tolerance is related to different dynamics of affect dysregulation and contributes to the onset and maintenance of psychopathology including suicide (e.g., Anestis, Pennings, Lavender, Tull, \& Gratz, 2013; Capron, Norr, Macatee, \& Schmidt, 2013). Even for those higher in distress tolerance, chronic and continuous stress and cumulative dynamics of traumatic and nontraumatic events can cause the victim to snap (Kira, Amer, \& Wrobel, 2014).

Karam et al., 2013, in large-scale cross-national database study of adults, found a risk threshold wherein cases with four or more traumas presented a more "complex" clinical picture with substantially greater functional impairment and greater morbidity than other cases. However, while such threshold of four or more can be helpful, we have to caution against it as it applies to the group not to the individual. Additionally the trauma scale they use did not include most systemic traumas (e.g., gender discrimination, ethnic discrimination) which are chronic, or attachment disruptions which are crucial for child and adult development.

C) Intersectionality of Systemic Traumas

Of special attention, in these cumulative dynamics is the intersection of different systemic traumas that target identity (e.g., discrimination and oppression). The effects of interlocking systems of oppression on an individual's life transcend the added experiences of each. DBTF proposes that a systemic trauma is amplified by such intersections and interactions and their linear and non-linear cumulative dynamics. Intersectionality is a term used to describe the intersecting effects of traumas with marginalizing characteristics that contribute to social identity. Different discrimination types intersect, reinforce and amplify each other (e.g., Seng, Lopez, Sperlich, Hamama, \& Meldrum, 2012). The combined effects of multiple systemic traumas that target individual's social identities on marginalization and associated negative self-dynamics (i.e., self-concepts, efficacy and functioning) can be deleterious. Chronic microaggressions (for example, insults), intermittent related macro-aggressions (for example, hate crimes), and proliferation and accumulation dynamics inherent in such traumas may contribute to its severity (Kira et al., 2013). Due to its chronicity and severity, type III trauma tends to be internalized, or resisted by affected individuals. Such "Internalization of inferiority can cause diminished self-capacity and efficacy and inferiority feelings that may be associated with poor physical, mental and quality of life" (Kira et al., 2013: p. 399). Internalization of comparative degraded status confirms and emphasizes the degraded self-concept and its related stereotypes and their consequences of diminished expectations and control, and decreased performance, that may yield post-trauma spectrum disorders (for example, PTSD, complex PTSD, Depression, and anxiety). Resistance may cause social or political conflict, or social pathology, a process that may be healthy 
or taxing.

D) Identity Annihilation Anxiety Related to Systemic and Identity Traumas

Another dynamic involved in systemic trauma (ST) is collective annihilation anxiety (AA). Because, systemic traumas are existential identity-based traumas, they may further elicit identity-related annihilation anxiety (AA). AA is a unique existential anxiety which is especially triggered by such collective and personal identity traumas (Winnicott, 1974; Hurvich, 2003; Kira et al., 2012a). Annihilation Anxiety AA was introduced in psychoanalytic, ego, self-psychology, and object relations psychology literature (e.g., Hurvich, 1989, 2003) and the construct goes back to existential philosophies of Sartre and Heidegger (e.g., Petot, 1976). Little or no attention in the psychoanalytic literature has been given to AA related to collective survival threats and its mental health effects (Kira et al., 2012a). There is evidence of the importance of such collective identity threats to mental health outcomes. For example, Nickerson, Bryant, Brooks, Steel, \& Silove, 2009, found that past trauma and symptoms of PTSD predicted fear of cultural extinction in a group of Iraqi refugee Mandaean minority in Australia. AA is redefined by Kira et al., 2012a, as a chronic terror of losing personal or/and social self or selves as a result of identity, personal or/and collective/group's survival threats. AA emerges from fears that one or more of the self-salient identities will be subsumed, devoured, dissolved or fused, penetrated, fragmented, destroyed, disappeared or subjugated, due to real or perceived threats to such salient identities' existence. According to DBTF, systemic trauma as an identity trauma can pose existential identity threats that may trigger AA.

\subsection{Backlash (Intense Targeted Multi-Systemic Discrimination and Oppression)}

Backlash trauma is special case of multi-systemic trauma and includes at least three sub-types of the four systemic traumas discussed earlier: intergroup (for example, verbal or non-verbal insults from neighbors or acquaintances and hate crimes because of group membership), institutional (for example, using security pretext to discriminate in employment, or harass by frequent pointless interviewing), and negative portrayals in the media (the effect of globalization). The involvement of some formal or informal agencies that promote the perceived discrimination is one of the characteristics of the backlash trauma (Kira et al., 2010b). Because of the intense multi-systemic discrimination perpetrated by such dominant institutions, it plausibly has more serious mental health consequences on exposed minorities than most other trauma types. While the mental health effects of BT on Japanese Americans have rarely been empirically assessed, their mental and physical health effects on adult Muslim mental health were found to be significant (Abu-Ras \& Suarez, 2009; Kira et al., 2010b).

\subsection{The Potential Mental Health Effects of MST and BT}

The negative effects of ST and MST on health are well documented (Major, Mendes, \& Dovidio, 2013). Wideranging systemic and social structural factors lead to devaluation of the lower strata via different mechanisms such as negative stereotypes, stigmatization, prejudice, discrimination, social identity threat and lowered expectations. Feelings of devaluation that accumulate, translate into lower self-esteem, self-efficacy, and associated negative psychophysiological processes, and ultimately into poor physical and mental health. BT is plausibly more severe with potentially more critical mental health outcomes, as it involves serious social exclusion and potential identity subjugation/annihilation threats.

While PTSD, in current literature is highly related to trauma exposure (TE), broad associations between multiple trauma exposure and Axis I psychopathology, other than PTSD, have been noted in the literature. In co-twin study Brown et al., 2013, found TE was significantly associated with greater likelihood of meeting criteria for major depression, dysthymia, anxiety, substance abuse, eating disorders, and somatization disorder. The potential post-traumatic stress reactions to systemic traumasmay go beyond single trauma reactions of PTSD, or major depression to other more complex syndromes. While some suggested new diagnostic disorders to be included in DSM to reflect the complexity of symptoms following complex traumas, e.g., extreme stress not otherwise specified (DESNOS) (Herman, 1992), developmental trauma disorder (van der Kolk, 2005) and continuous traumatic stress syndrome (Straker et al., 1987), others have suggested a different approach that introduces co-morbidity models combining diagnostic categories into syndromes or profiles of comorbid disorders, for example: internalizing and externalizing disorders (Sack et al., 1999) and the cumulative trauma disorder (CTD) model in refugees and torture survivors, (Kira et al., 2012). Such comorbidity models are trans-diagnostic concepts that assume that different cumulative trauma profiles yield different profiles of co-morbid diagnostic categories and syndromes. CTDs have been found to be prevalent in adult and child refugees (Kira et al., 2008a; Ki- 
ra, 2010b; Kira et al., 2012b). Internalizing and externalizing disorders are other co-morbid trans-diagnostics that have been more evident in child refugees (Bronstein \& Montgomery, 2011).

There is growing literature on exposure to ethnic-political violence and discrimination in different populations that can certainly be qualified as systemic trauma (e.g., Dubow et al., 2012; Canetti et al., 2010; Greene, Way, \& Pahl, 2006; Williams \& Mohammed, 2009). Further, much of this literature follows a social-cognitive-ecological framework that also accounts for traumatic experiences across ecological levels. However, most of such important research lacks a clear trauma framework that can frame its outcome accurately.

Previous studies that measured the effects of discrimination after September 11, 2001 on Arab and Muslim Americans using different measurement tools found that discrimination is generally associated with psychological distress without detailed assessment of its impact (Abdulrahim, James, Yamout, \& Baker, 2012; Abu-Ras, \& Suarez, 2009; Moradi \& Hasan, 2004; Rousseau, Hassan, \& Moreau, 2011; Padela, \& Heisler, 2010; for review, see: Amer \& Bagasra, 2013). Exceptions are few adult studies that assessed in more details its mental and physical health impact (Abu-Ras \& Suarez, 2009; Kira et al., 2010).

\subsection{The Effects of Backlash on Iraqi Refugee Muslim Adolescents in the US}

Iraqi refugee families have experienced high doses of violence, oppression, and torture in their own country of origin before arriving to the US. They have been displaced and sent to refugee camps. They have had multiple losses of family members and friends many "disappearing" without a trace (Kira et al., 2006, 2007). As they travel to the US, Iraqi families face acculturation stresses, learning a new language and culture. Once in the US they have been confronted with discrimination and the international war on terrorism (Kira et al., 2007, 2008a).

Iraqi refugee adolescents in the US endured both primary and secondary traumas. They endured secondary trauma of their tortured, oppressed and uprooted parents (Kira et al., 2006, 2007), as well as the primary trauma of backlash and discrimination. They are in the phase of identity development and such collective identity traumas of backlash that mostly target identity and have potentially more negative effects on their identity development (Sirin \& Fine, 2007) and mental and physical health. However, the effects of BT on Iraqi and Muslim adolescents' mental health have never been empirically investigated. Studying the effects of backlash on Iraqi adolescents will elucide the potential effects on similar other Muslim and Middle Eastern adolescents in general.

\subsection{Study Goals}

The goal of the current research is to study the differential effects of multi-systemic backlash trauma that emerged after the September 11 attacks, compared to other trauma types on a group of Iraqi refugee Muslim adolescents in the US, utilizing the DBTF framework that includes both systemic and non-systemic based traumas. The goal is to better understand the nature and the effects of such trauma types on mental health and test the utility and validity of the basic assumptions of DBTF on systemic traumas.

\subsection{Hypotheses}

Hypothesis 1: Because BT is a chronic collective identity trauma related to interdependence dynamics, it was predicted to be more strongly associated with other identity traumas, secondary traumas, chronic (non-traumatic) stress and less strongly associated with attachment and family related traumas (intersectionality hypothesis).

Hypothesis 2: In accordance with the severity/chronicity hypotheses implied in DTBF (BT is traumatic and chronic), BT was predicted to be associated of PTSD, CTD, AA, internalizing and externalizing disorders after controlling for previous life time traumas and the demographic variables of age, gender, and socioeconomic status (SES). The negative mental health effects of BT were predicted to be relatively more severe compared to other non-systemic trauma types.

\section{Method}

Participants were 224 Iraqi refuge adolescents. Their age ranged from 12 - 17 ((M (SD) = 13.49 (1.59)). All participants were students from different schools in Dearborn and Detroit, Michigan, with $46 \%$ belonging to grades 5 to 7 and $54 \%$ belonging to the grades 8th-12th. Among them, 52.5\% were males and $47 \%$ females, $98.6 \%$ were Muslim Shiites and the rest were Muslim Sunni. For perceived level of poverty, $10.6 \%$ reported that they 
belong to "a very poor family" that "had multiple hardships", 12.3\% indicated they were "somehow poor", 45.5\% indicated that they are "not very poor" (in the middle), while 31.6\% indicated that their families are "financially sound".

\subsection{Measures}

\subsubsection{Predictor Variables Measures}

Cumulative Trauma Scale-Long Version (CTS-L-A)-(Adolescent Version) includes 61 items and is based on the DBTF (Kira, 2001; Kira et al., 2008a). Each item describes an extremely stressful event that belongs to 6 different types of traumas: attachment (e.g., abandonment by mother), personal identity (for example rape), collective identity (for example discrimination and oppression), secondary (interdependence) (for example witnessing, watching, or listening to, compassion fatigue), survival (physical identity) (attacked by a weapon, hurricane), and role identity or achievement traumas (for example loss of job or failed business, or failed in school). The items were focused on lifetime occurrence of each trauma. Example items are "I was led to sexual contact by one of my caregiver/parents" and "my mother has abandoned or left/or was separated from me when I was a child". The measure includes a single item for chronic non-traumatic stress (hassles): "I experienced a nervous breakdown or felt like I was about to have one (e.g., about to lose control) due to seemingly small but recurrent or continuous chronic stresses or hassles". On each item, the participant is asked to report if he/she has experienced the stressor, how many times he/she experienced the event on a 5-point Likert scale $(0=$ never, $4=$ many times), the age when he/she first experienced the stressor, and then to indicate, how much it affected him or her either positively or negatively on a scale from 1 (extremely positive) to 7 (extremely negative). In the analysis, the appraisal scale was divided into two sub-scales: positive appraisal (1 - 4) and negative appraisal (5 7). The measure provides us with two scales for trauma dose: occurrence (happened or not happened) and frequency of happenings (if it happened, how many times), two appraisal sub-scales: negative and positive appraisals for each trauma. This scoring enables us to obtain four sub-scales for each traumatic event, for each trauma type and for cumulative trauma (total score). The measure had been used previously with different clinical and community populations of adults and children to measure trauma types, cumulative trauma and appraisal. It proved to have adequate reliability (Alpha of $.80-.90$ ), good construct and predictive validity (Kira et al., 2008a, 2008b; Kira et al., 2011). We used the occurrence sub-scale in the current study. The reliability of the CTS occurrence measure was found adequate in the current study (alpha $=.88$ ). While the collective identity sub-scale measures systemic traumas in general, it does not measure the particular specific multi-systemic backlash targeting Muslim Americans after the September 11, 2011 attacks.

Revised Race Related Stressors Scale (Backlash Trauma, BT)—RRSS. RRSS was developed by Loo and associates (2001) and has proved to be reliable and valid (alpha $=.97$ ) with Asian American veterans. This 18-items scale was modified (for adults and adolescents) to measure the degree of exposure, in the last year, to specific situations that indicate intensified discrimination and racism against Muslim Americans (Kira et al., 2010b). Examples of the items are: I or my children (or a parent) have been called racial slurs like camel Jockey or, some American institutions and media treated Arabs and Muslims as if their lives were of lesser value than American lives; authorities questioned me because of being Arab or Muslim American. The participants were asked to rate each situation according to a five point scale with 1 indicating that the situation does not exist and 5 indicating that it is very much happening. The BT Scale has been found to have high reliability (alpha of .95) and strong evidence for construct, convergent, divergent, and predictive validity in a previous study on Iraqi refugee adults (Kira et al., 2010b). It was found to have three sub-scales: Interpersonal backlash (intergroup), media backlash, and institutional/governmental backlash (Kira et al., 2010b). The sub-scales represented three of the four systemic traumas: Inter-group, institutional and globalization-based systemic traumas. In the current study, the scale's alpha is .91 , while alphas for its sub-scales are $.90, .89$ and .83 respectively.

\subsubsection{Dependent Variables Measures}

Clinician-Administered PTSD Scale (CAPS-2) (Blake et al., 1990) is widely used to assess PTSD. It is a structured clinical interview that assesses 17 symptoms rated on frequency and severity on a 5-point scale. The CAPS-2 assessed one week symptom status. CAPS demonstrated high reliability with a range from $.92-.99$ and showed good convergent and discriminant validity. It has four factor sub-scales: re-experiencing, avoidance, arousal and emotional numbness, and detachment or dissociation (Palmieri, Weathers, Difede, \& King, 2007). In 
this study, we used the frequency sub-scale of CAPS-2 that is currently widely used in psychiatric literature. Elhai et al. (2006) found that the two symptom formats were highly intercorrelated (from .86 to .93) and were not differentially related to summed PTSD severity scores or PTSD diagnoses. In addition, Betemps, Smith, Baker, and Rounds-Kugler (2003) discovered that the frequency format was associated with both greater reliability and item discrimination than the intensity format. It has high reliability with an alpha of .97 in current data. We previously piloted it in a focus group of Arab American Adolescents and found to be appropriate for this group. We used the total score to indicate PTSD symptoms severity.

Annihilation Anxiety Scale (AA) (Kira et al., 2012c) is based on the assumption that there are at least three main sources of the emergence of annihilation threats: personal identity, collective identity and threats from severe societal structural inequalities. Three items that represent the three components were used, for example, "because of what has happened to me personally or is happening to me personally, I sometimes worry that I just lose my sense of self (I worry that I will cease to exist as an individual person).” The answer was structured on a 5 point-Likert-scale (5. Strongly Agree; 4. Agree; 3. Not Sure; 2. Disagree; 1 . Strongly Disagree). The 3-item scale has been previously used on Iraqi refugees in Michigan and on three samples of Palestinians adults and adolescents, as well on the initial validation study on mental health clients $(\mathrm{N}=399)$. In the initial validation study, and following studies, its alpha reliability ranged between .90 - .95, and its convergent, discriminant and predictive validity was adequate (Kira et al., 2012c). In the validation study, using multiple regression, while all trauma types predicted AA, collective identity trauma was the highest predictor $\left(\beta=.74^{* * *}\right)$. Negative appraisal of different survival and identity traumas was a stronger predictor of AA than just the occurrence of the traumas. AA was found to be a significant predictor of PTSD $\left(\beta=.46^{* * *}\right)$, cumulative trauma disorder (CTD) $\left(\beta=.43^{* * *}\right)$, general anxiety $\left(\beta=.40^{* * *}\right)$, depression $\left(\beta=.38^{* * *}\right)$, and poor self-rated health $\left(\beta=.14^{* *}\right)$. AA mediated the effects of cumulative negative appraisal on mental and physical health. AA was highly associated with CTDDissociation/Psychosis Sub-scale. Similar strong results were found in subsequent studies on Palestinian adolescents and adults (Kira et al., 2013). It has an alpha of .93 in the current study.

Cumulative Trauma Related Disorders Measure (CTD) (or complex PTSD) (Kira et al., 2012b): This 15 item measure has been developed on five community and clinic samples of adults, adolescent Arab and African Americans. It is an index measure that covers 13 symptom categories: depression, anxiety, somatization, dissociation, auditory and visual hallucinations, avoidance of being with people, paranoid ideations, concentration and memory deficits, loss of self-control, feeling suicidal, and feeling like hurting self. Exploratory and confirmatory factor analysis found four factors (four sub-scales): Executive function deficits and loss of control, suicidality, dissociation/psychosis, and depression/ anxiety/somatization comorbidity (Kira et al., 2012b). It has good reliability (ranged from .85 and .98). Test-retest reliability in a 6 week-interval was .76. The measure has good concurrent, discriminant and predictive validity. Different kinds of traumas, and cumulative trauma "in general" accounted for significant variance as predictors of CTD symptoms. In previous studies, it was highly associated with comorbidity of mental disorders. In the current data, its alpha was .91 and .95, .97, .98, and .96 respectively for its sub-scales.

The Adolescent Psychopathology Scale-Short Form (APS-SF) (Reynolds, 2000) is 115 items and was developed to assess the indicators of psychological disorders in adolescents. The APS-SF examines domains of psychopathology and psychosocial problems. It is made up of 12 clinical sub-scales and 2 validity scales (defensiveness and inconsistency). Six scales are correlated with DSM-IV stipulations which include: General Anxiety Disorder, Conduct Disorder, Major Depression, Post Traumatic Stress Disorder, Oppositional Defiant Disorder, and Substance Abuse Disorder. These scales provide an indication of possible disorders, not a formal diagnosis. The other six APS-SF clinical sub-scales which are not associated with specific DSM-IV disorders include: anger/violence proneness, academic problems, suicide, interpersonal problems, self-concept, and eating disorders. All sub-scales were found to have good validity. The internal consistency for the sub-scales in standardized sample ranged from 80 to 91 , with test-retest reliability ranging from 76 to 91 (14 day interval). APS-SF has two dimensional index scales: internalizing disorders (generalized anxiety disorder, PTSD, major depression, eating disorder, suicide, self-concept and interpersonal problems) and externalizing disorders (conduct disorders, oppositional defiant disorder, substance abuse disorder, anger/violence, and academic problems).

\subsection{Procedure}

Participants were part of a bigger study that investigated the effects of different traumas on African American 
and Iraqi refugee adolescents (Kira et al., 2012e), and were all English speaking. Approval to conduct human subjects' investigations for this study was obtained from the principal investigator's designated Institutional Review Board prior to data collection. Written informed consents from parents and assents from adolescents were obtained. Iraqi adolescents were recruited through local Arab community centers, utilizing their lists of phone numbers of Iraqi families. The Snowballing sampling technique was utilized in the recruitment process which took place over four weekends between the months of September and November in 2006. Face-to-face interviews were conducted individually in private rooms located in the libraries and offices of a university campus. Interviews were conducted by licensed mental health professionals in four weekend testing days. Between 100 120 students on each of the four testing and retreat days were divided, for cultural reasons, into five girl groups and five boy groups for a total of 10 groups. These 10 groups rotated between five testing stations for a five hour a day of data collection period as part of an entire day of retreat activities. (Additional measures not reported in this article were also administered). A gift certificate of 25 dollars and a magic show during lunch were provided as incentives for participation.

\subsection{Analysis}

To explore the associations between BT and other trauma types and with post-trauma spectrum disorders and to determine which trauma had relatively more of a mental health impact, we conducted partial correlations between BT, all trauma types, PTSD, CTD, AA, and internalizing and externalizing disorders. We controlled for gender, age and level of poverty. Further, to measure the effects of backlash trauma (BT) and its types on PTSD and CTD, we conducted hierarchical multiple regression analyses. In the hierarchical regression model, we entered age, gender, and level of poverty (SES) in the first block to control for their effects. We added cumulative life traumas in the second block to measure and control for their effects, and backlash trauma (BT) or one of its types in the third block, to unpack the link between BT, as well as each of its types and PTSD and CTD after isolating the effects of other trauma types and demographics. We used IBM-SPSS 20 statistical package to conduct the analyses. We tested for multi-colinearity. VIF (variance inflation factor) for all predictor variables ranged between less than 1.00 and 1.50which indicated low colinearity (O'Brien, 2007).

\section{Results}

\subsection{Descriptive Results}

Participants were multiply traumatized (mean types of traumas occurrence [SD] is 8.35[3.34], and 13.95[6.19] for trauma frequency). Only one participant did not report any trauma occurrence, while the rest reported between 5 and 26 trauma types. While $50 \%$ reported different levels of cumulative negative appraisal of their traumas $(M=9.58, S D=32.02), 83.5 \%$ reported different degrees of cumulative positive appraisal $(M$ $=9.13, S D=20.96)$. Participants seem to be relatively more positive in appraising the effects of their traumas.

Their highest exposure was to secondary traumas (e.g. parents torture) $(M=1.86, S D=1.64)$, followed by survival traumas $(M=.40, S D=.78)$, personal identity traumas $(M=.32, S D=.61)$, collective identity trauma $(M=.28, S D=.68)$, abandonment or separation from parents $(M=.13, S D=.38)$, and achievement traumas $(M$ $=.12, S D=.32)$. The least trauma types that was suffered was family traumas $(M=.10, S D=.32)$.

For backlash traumas, Iraqi refugee adolescents in this sample have been exposed to a relatively high load of discrimination related to backlash $(M=27.67, S D=16.92)$. The highest exposure was to interpersonal backlash $(M=13.51, S D=5.98)$, followed by media backlash $(M=7.80, S D=5.19)$, and active government institution backlash $(M=4.90, S D=2.41)$. While over $58 \%$ reported at least 21 total microaggression incidents $(21-133)$, $65.5 \%$ reported 11, and the rest reported 12 to 52 interpersonal microaggression incidents. All participants reported 5 to 42 media microaggression incidents, and 3 to 20 institutional microaggressions.

\subsection{Correlational Results}

Hypothesis 1: Because BT is a chronic collective identity trauma related to interdependence dynamics, it was predicted to be more strongly associated with other identity traumas, with chronic (non-traumatic) stress as well as secondary traumas and less strongly associated with attachment and family related traumas (intersectionality hypothesis). 
BT and its sub-scales were highly associated with identity traumas ( $r=.42, p<.001$, with collective identity), (.36, $p<.001$, with personal identity), with chronic stress $\left(r=.42^{* * *}, p<.001\right)$, as well as with interdependence (secondary) traumas $(\mathrm{r}=.35, p<.001)$. BT was less associated with survival $(r=.19, p<.05)$, and attachment traumas $(r=.18, p<.05)$, and to some degree with role identity (achievement) traumas $(r=.17, p<.05)$ and not significantly associated with family traumas (Table 1 ).

Hypothesis 2: In accordance with the severity/chronicity hypotheses implied in DTBF (BT is traumatic and chronic), BT was predicted to be associated with PTSD, CTD, AA, internalizing and externalizing disorders after controlling for other previous life time traumas and the demographic variables of age, gender, and SES. The negative mental health effects of BT were predicted to be relatively more severe compared to other non-systemic trauma types.

Partial correlations, controlling for age, gender and SES, indicated that Backlash Trauma (BT) and different backlash types were significantly associated with PTSD, especially interpersonal (inter group) $(r=.50, p$ $<.001)$, and institutional/ governmental backlash $(r=.48, p<.001)$. Dissociation/ emotional numbness seems to be the highest symptom cluster of PTSD that is associated with the interpersonal backlash $(\mathrm{r}=.60, p<.001)$, and institutional backlash $(r=.56, p<.001)$. Similar results were found for CTD and its syndromes. The most CTD associated syndromes were: executive function deficits with total BT $(r=.57, p<.001)$, institutional BT ( $r$ $=.60, p<.001)$, and media BT $(r=.57, p<.001)$. Depression/anxiety/somatization comorbidity was associated with interpersonal BT ( $r=.46, p<.001)$, as well as with institutional BT. Dissociation/ psychosis comorbidity was strongly associated with interpersonal (intergroup) BT $(r=.43, p<.001)$. The same pattern was found for the association with annihilation anxiety (AA). While media BT associations, in general, were less strong, BT was significantly associated with PTSD $(r=.28, p<.001)$, CTD $(r=.38, p<.001)$, executive function deficits $(r=.47, p<.001)$ and AA $(r=.24, p<.01)$.

For APS scales, interpersonal (intergroup) problems were highly associated with PTSD $(r=.58, p<.001)$, major depression (MDD) $(r=.57, p<.001)$, and generalized anxiety disorder (GAD) $(r=.56, p<.001)$, followed by eating disturbances $(r=.44, p<.001)$, suicide $(r=.38, p<.001)$, academic problems $(r=.45, p$ $<.001)$, anger violence proneness $(r=.44, p<.001)$, oppositional defiant symptoms $(r=.40, p<.001)$, and conduct disorder $(r=.25, p<.05)$. PTSD, MDD and GAD were also highly associated with institutional/governmental backlash $(r=.42, p<.001, r=.41, p<.001, r=.43, p<.001$ respectively), followed by eating disturbances $(r=.44, p<.001)$, suicide $(r=.44, p<.001)$, academic problems $(r=.32, p<.01)$, anger violence proneness $(r=.39, p<.001)$, and oppositional defiant symptoms $(r=.26, p<.01)$. Media backlash was specially associated with interpersonal problems $(r=.37, p<.001)$, followed by major depression $(r=.30, p$ $<.01)$,eating disorders $(r=.29, p<.01)$, PTSD $(r=.27, p<.01)$, suicide $(r=.26, p<.01)$, and anger violence proneness $(r=.21, p<.05)$. The cumulative effects of the total backlash trauma covered all disorders except self-concept and substance abuse disorders (Table 1). Cultural and religious reasons may be factors, as the Muslim religion and Muslim cultures prohibit substance abuse.

Total BT, interpersonal BT and institutional BT were significantly associated with internalizing $(\mathrm{r}=.37, p<.001)$ $(r=.41, p<.001),(r=.30, p<.001)$ and externalizing disorders $(r=.24, p<.01)(r=.29, p<.01)(r=.18, p<.05)$ respectively. Media BT was significantly associated with internalizing disorders only $(r=.25, p<.01)$ (Table 1$)$.

Results of a hierarchical regression indicated that after controlling for demographics and all cumulative life traumas measured, total backlash highly predicted PTSD $(\beta=.28, p<.001)$ and especially the more complex syndromes of CTD $(\beta=.34, p<.001)$ (Table 2). Governmental (institutional) and interpersonal (intergroup) backlash seem to be the most instrumental of the suffering compared to media backlash that was still significantly associated with PTSD and CTD (Table 3).

While BT was significantly correlated with annihilation anxiety (AA; .30, $p<.001)$ and predicted AA before introducing cumulative life trauma in the hierarchical regression equation, contrary to the study hypothesis, BT did not predict AA after controlling for cumulative life trauma and demographics. Cumulative life trauma was the robust predictor of such existential anxiety $(\beta=.85, p<.0001)$ (Table 4).

Collective identity trauma was correlated with PTSD (.17, $p<.05) \operatorname{CTD}(.27, p<.001)$, and AA $(.24, p<.01)$. Personal identity trauma correlated with PTSD $(.22, p<.01)$ CTD $(.23, p<.01)$, and AA $(.23, p<.01)$. Interdependence traumas trauma correlated with PTSD (.28, $p<.001)$ CTD $(.26, p<.01)$, and AA $(.22, p<.01)$. Attachment and family traumas did not correlate significantly with PTSD, CTD or AA. Survival trauma correlated with PTSD (.22, $p<.01)$, CTD $(.28, p<.001)$, and did not correlate significantly with AA. Achievement trauma correlated with CTD $(.19, p<.05)$, and did not correlate significantly with PTSD or AA. 
While most of these trauma types had serious mental health effects as expected, BT compared to those other trauma types (collective identity, personal identity, attachment, family survival, and achievement and interdependence traumas) was the most strongly correlated with PTSD $(.37, p<.001)$, CTD $(.48, p<.001)$ and AA $(.30$, $p<.001$ ), as well as to other sub-measures of APS. Only cumulative trauma occurrence was correlated the most strongly with AA $(.75, p<.001)$, and PTSD $(.38, p<.001)$ (Table 3$)$. The only comparable stress variable concerning BT severity is chronic (non-traumatic) stress. Chronic stress was significantly associated with PTSD $(.39, p<.001)$, CTD $(.41, p<.001)$ and AA $(.40, p<.001)$.

\section{Discussion}

The primary purpose of this study was to test the utility and validity of systemic type III trauma and its assumptions

Table 1. Partial correlations (controlling for gender, age and SES) between backlash multi-systemic traumas, other trauma types and mental health variables in Iraqi refugee adolescents.

\begin{tabular}{|c|c|c|c|c|}
\hline & $\begin{array}{l}\text { Interpersonal } \\
\text { Backlash }\end{array}$ & $\begin{array}{c}\text { Media } \\
\text { Backlash }\end{array}$ & $\begin{array}{l}\text { Institutional and } \\
\text { Government Backlash }\end{array}$ & $\begin{array}{c}\text { Total } \\
\text { Backlash }\end{array}$ \\
\hline Annihilation Anxiety (AA) & $.32^{* * *}$ & $.27^{* * *}$ & $.24^{* * *}$ & $.30^{* * *}$ \\
\hline PTSD & $.50^{* * *}$ & $.28^{* * *}$ & $.48^{* * *}$ & $.37^{* * *}$ \\
\hline CTD & $.58^{* * *}$ & $.38^{* * *}$ & $.57^{* * *}$ & $.49^{* * * *}$ \\
\hline PTSD-Re-Experiencing & $.44^{* * *}$ & $.25^{* *}$ & $.41^{* * *}$ & $.33^{* * *}$ \\
\hline PTSD-Arousal & $.23^{* *}$ & .09 & $.17^{*}$ & $.14^{*}$ \\
\hline PTSD-Avoidance & $.36^{* * *}$ & $.18^{*}$ & $.38^{* * *}$ & $.27^{* * *}$ \\
\hline PTSD-Dissociative Numbness & $.60^{* * *}$ & $.38^{* * *}$ & $.56^{* * *}$ & $.43^{* * *}$ \\
\hline CTD-Suicidality & $.30^{* * * *}$ & .09 & $.32^{* * *}$ & $.20^{*}$ \\
\hline CTD-Dissociation and Psychotic Symptoms & $.43^{* * *}$ & $.27^{* * *}$ & $.36^{* * *}$ & $.31^{* * *}$ \\
\hline CTD-Executive Function Deficits & $.57^{* * *}$ & $.47^{* * *}$ & $.60^{* * *}$ & $.57^{* * * *}$ \\
\hline CTD-Depression/Anxiety/Somatization Comorbidity & $.46^{* * *}$ & $.26^{* * *}$ & $.46^{* * *}$ & $.39^{* * *}$ \\
\hline Collective Identity Traumas & $.46^{* * *}$ & $.25^{* *}$ & $.37^{* * *}$ & $.42^{* * *}$ \\
\hline Personal Identity Trauma & $.34^{* * *}$ & $.30^{* * *}$ & $.29^{* * *}$ & $.36^{* * *}$ \\
\hline Attachment Disruption Traumas & $.19^{*}$ & .15 & $.26^{*}$ & $18^{*}$ \\
\hline Family Traumas & -.07 & -.05 & -.09 & -.08 \\
\hline Survival Traumas & $.23^{* *}$ & .12 & $.22^{*}$ & $.19^{*}$ \\
\hline Interdependence Traumas & $.37^{* * *}$ & $.23^{* *}$ & $.36^{* * *}$ & $.35^{* * *}$ \\
\hline Achievement Traumas & $.24^{* * *}$ & .07 & $.18^{*}$ & $.17^{*}$ \\
\hline Cumulative Trauma & $.47^{* * *}$ & $.30^{* * *}$ & $.44^{* * *}$ & $.44^{* * *}$ \\
\hline Chronic Stress & $.40^{* * *}$ & $.30^{* * *}$ & $.33^{* * *}$ & $.42^{* * *}$ \\
\hline APS-Conduct Disorder & $.25^{*}$ & .09 & .07 & $.27^{*}$ \\
\hline APS-Oppositional Defiant Disorder & $.40^{* * *}$ & .20 & $.26^{*}$ & $.41^{* * *}$ \\
\hline APS-Substance Abuse Disorders & -.05 & -.03 & -.02 & -.04 \\
\hline APS-Anger Violence Proneness & $.44^{* * *}$ & $.21^{*}$ & $.39^{* * *}$ & $.46^{* * *}$ \\
\hline APS-Academic Problems & $.45^{* * *}$ & .15 & $.32^{* *}$ & $.47^{* * *}$ \\
\hline APS-Generalized Anxiety Disorder & $.56^{* * *}$ & .23 & $.43^{* * *}$ & $.56^{* * *}$ \\
\hline APS-Posttraumatic Stress Disorder & $.58^{* * *}$ & $.27^{*}$ & $.42^{* * *}$ & $.59^{* * * *}$ \\
\hline APS-Major Depression & $.57^{* * *}$ & $.30^{*}$ & $.41^{* * *}$ & $.59^{* * * *}$ \\
\hline APS-Eating Disturbance & $.44^{* * *}$ & $.29^{*}$ & $.44^{* * *}$ & $.41^{* * *}$ \\
\hline APS-Suicide & $.38^{* * *}$ & $.26^{*}$ & $.44^{* * *}$ & $.41^{* * *}$ \\
\hline Self-concept & .10 & .11 & .11 & .10 \\
\hline APS-Interpersonal Problems & $.48^{* * *}$ & $.37^{* *}$ & $.45^{* * *}$ & $.53^{* * *}$ \\
\hline APS-Defensiveness & $.30^{* *}$ & .17 & $.32^{* *}$ & $.30^{*}$ \\
\hline Internalizing Disorders & $.41^{* * *}$ & $.25^{* *}$ & $.30^{* * *}$ & $.37^{* * *}$ \\
\hline Externalizing Disorders & $.29^{* * *}$ & .09 & $.18^{*}$ & $.24^{* *}$ \\
\hline
\end{tabular}

Note: ${ }^{*} p<.05 ; \stackrel{* *}{p}<.01 ;{ }^{* * *} p<.001$ (two-tailed). 
Table 2. Hierarchical regression summary with PTSD, CTD as dependent variables and age, socio-economic status (SES) and gender, in the first block, added cumulative trauma in the second block and added backlash (B) in the third block ( $\mathrm{N}=$ 224).

\begin{tabular}{|c|c|c|c|c|c|c|c|c|}
\hline \multirow{2}{*}{$\begin{array}{c}\text { Dependent Variables } \\
\text { Predictors Entered }\end{array}$} & \multicolumn{4}{|c|}{ PTSD } & \multicolumn{4}{|c|}{ CTD } \\
\hline & B & SE (B) & $\beta$ & $\mathrm{R}^{2}$ (R $\mathrm{R}^{2}$ Change) & B & SE (B) & $\beta$ & $\mathrm{R}^{2}$ ( $\mathrm{R}^{2}$ Change) \\
\hline \multicolumn{9}{|l|}{ First Step } \\
\hline Gender & 1.49 & 1.48 & .09 & \multirow{3}{*}{$.015(.015)$} & 3.96 & 1.14 & $.28^{* * *}$ & \multirow{3}{*}{$.099(.099)^{* * *}$} \\
\hline Age & .39 & .49 & .07 & & .64 & .38 & .13 & \\
\hline SES & .50 & .79 & .05 & & .28 & .60 & .04 & \\
\hline \multicolumn{9}{|l|}{ Second Step } \\
\hline Gender & 1.77 & 1.38 & .10 & \multirow{4}{*}{$.145(.130)^{* * *}$} & 4.11 & 1.04 & $.29^{* * *}$ & \multirow{4}{*}{$.250(.151)^{* * *}$} \\
\hline Age & -.02 & .46 & -.004 & & .31 & .35 & .07 & \\
\hline SES & -1.55 & .86 & $-.17^{*}$ & & -1.52 & .65 & $-.20^{*}$ & \\
\hline Cumulative Trauma & .67 & .15 & $.43^{* * *}$ & & .59 & .11 & $.46^{* * *}$ & \\
\hline \multicolumn{9}{|l|}{ Third Step } \\
\hline Gender & 1.46 & 1.34 & .08 & & 3.72 & .99 & $.26^{* * *}$ & \\
\hline Age & -.17 & .45 & -.03 & & .19 & .33 & .04 & \\
\hline SES & -1.15 & .84 & -.12 & $.206(.062)^{* * *}$ & -1.20 & .61 & $-.16^{*}$ & $.340(.089)^{* * *}$ \\
\hline Cumulative Trauma & .45 & .16 & $.29^{* * *}$ & & .37 & .12 & $.29^{* * *}$ & \\
\hline Total Backlash & .16 & .05 & $.28^{* * * *}$ & & .15 & .04 & $.34^{* * *}$ & \\
\hline
\end{tabular}

Note ${ }^{*} p<.05 ; \stackrel{* *}{p}<.01 ;{ }^{* * *} p<.001$ (two-tailed).

Table 3. Partial correlations between different trauma types, PTSD, CTD and annihilation anxiety (controlling for gender, age and SES).

\begin{tabular}{|c|c|c|c|}
\hline Trauma Types & PTSD & CTD & Annihilation Anxiety \\
\hline Collective Identity Traumas & $.17^{*}$ & $.27^{* * *}$ & $.24^{* *}$ \\
\hline Personal Identity Traumas & $.22^{* *}$ & $.23^{* *}$ & $.23^{* *}$ \\
\hline Interdependence (Secondary) Traumas & $.28^{* * *}$ & $.26^{* *}$ & $.22^{* *}$ \\
\hline Survival Traumas & $.22^{* *}$ & $.28^{* * *}$ & .08 \\
\hline Attachment Traumas & .13 & .08 & .08 \\
\hline Family Traumas & .09 & .01 & .13 \\
\hline Achievement Traumas (Role Identity traumas) & .14 & $.19^{*}$ & .04 \\
\hline Chronic Stress & $.39^{* * *}$ & $.41^{* * *}$ & $.40^{* * *}$ \\
\hline Cumulative Traumas Occurrence & $.38^{* * *}$ & $.40^{* * *}$ & $.75^{* * *}$ \\
\hline
\end{tabular}

Note: ${ }^{*} p<.05 ;{ }^{* *} p<.01 ;{ }^{* * *} p<.001$ (two-tailed).

on a sample of Muslim Iraqi refugee adolescents who suffered from backlash (a multi-systemic trauma) against Mus $\lim$ Americans after the September 11, 2001, attacks. The current study was one of the first to examine the mental health effects of discrimination and backlash (that involved some government systems participation) against minorities from a systemic trauma perspective. The current study is the first to highlight the extent of potential suffering that minorities endured in history and in present from this type of backlash such as in the case of Japanese Americans after Pearl Harbor (Daniels, Taylor, \& Kitano, 1991), as well as other unfortunate examples in history and in contemporary societies where such backlash against minorities may exist.

Most of the previous studies that measured the effects of discrimination after September 11, 2001 on adolescents were limited in scope (e.g., did not measure official systems participation in the backlash), and the outcome variables measured did not represent the spectrum of post-trauma disorders (for review see Amer \& Bagasra, 2013). In the current study, multi-systemic chronic type III backlash trauma was not only associated with a number of post-trauma spectrum disorders of PTSD, CTD, and AA and had strong associations with internalizing and externalizing disorders, but also had a stronger relationship with other identity traumas as compared to attachment and family related (types I and II) traumas. BT had relatively stronger relationships with post-trauma 
Table 4. Hierarchical regression summary with annihilation anxiety as dependent variable and age, socio-economic status (SES) and gender, in the first block, added total backlash in the second block and cumulative trauma in the third block ( $\mathrm{N}=$ 224).

\begin{tabular}{ccccc}
\hline Dependent Variables & & & & Annihilation Anxiety \\
\hline Predictors Entered & $\mathrm{B}$ & $\mathrm{SE}(\mathrm{B})$ & $\beta$ & $\mathrm{R}^{2}\left(\mathrm{R}^{2}\right.$ Change $)$ \\
\hline First Step & & & & \\
Gender & -.17 & .34 & -.03 & $.224(.224)^{* * *}$ \\
Age & .06 & .11 & .03 & \\
SES & -1.25 & .16 & $-.49^{* * *}$ & \\
Second Step & & & & $.261(.037)^{* * *}$ \\
Gender & -.20 & .33 & -.04 & \\
Age & .01 & .11 & .01 & \\
SES & -1.23 & .15 & $-.48^{* * *}$ & \\
Backlash Trauma & .02 & .01 & $.14^{*}$ & $.685(424)^{* * *}$ \\
Third Step & & & & \\
Gender & -.14 & .22 & -.03 & \\
Age & -.07 & .07 & -.04 & \\
SES & -.26 & .12 & $-.10^{*}$ & \\
Total Backlash & -.01 & .01 & -.08 & $.79^{* * *}$ \\
Cumulative Trauma & .35 & .02 &
\end{tabular}

Note: ${ }^{*} p<.05 ;{ }^{* *} p<.01 ;{ }^{* * *} p<.001$ (two-tailed).

spectrum disorders compared to their relationships with attachment and family traumas. Only cumulative life trauma occurrence (type IV trauma) was more strongly correlated with AA as compared to backlash. BT is atype III identity trauma, perpetrated by influential dominant social institutions. It is continuous, on-going and tends to proliferate. It threatens the social inclusion of the victims and their identity. Because of all these characteristics, it may present more significant and negative mental health outcomes as compared to types I and II traumas that have occurred in the past, cease to occur, and do not tend to involve such serious social and group identity threats.

While the BT scale used in the current study included only three of the four components of systemic traumas identified in the introduction - intergroup, institutional, and globalization — the fourth component, social structural violence (e.g., SES or poverty), was introduced, partly, in the hierarchical regression model as one of the demographic variables. Some demographic characteristics, such as SES, were used in research as proxies for social structural violence "inequalities". SES was also found to be predictive of PTSD, CTD and AA after controlling for other demographics and cumulative traumas. That lends support to the assumption that social structural violence, the fourth component of systemic traumas discussed in our model, has extremely negative mental health effects.

Additionally, the study detailed the differential negative effects of different systemic traumas in this population. Intergroup, institutional and social-structure systemic traumas were found to have stronger negative rela-tionships with mental health disorders as compared to media (globalization) effects. Media BT had a pattern of weak but significant negative relationships with mental health. However, the media-related BT seems to impact and exacerbate the existing interpersonal problems in adolescents, as it was highly associated with such problems.

BT was initially significant predictor of annihilation anxiety (AA). However, when we controlled for cumulative trauma and demographics it lost its significance. Cumulative trauma (type IV trauma) was the robust predictor of such existential anxiety in this adolescent population, followed by socio-economic status (poverty as social structure violence). This may validate some of the basic assumptions of DBTF intensity/chronicity dimension. Cumulative trauma that includes all systemic and non-systemic, past, present and chronic traumatic and non-traumatic stress seems to be the strongest predictor of such strong existential distress and on potential threat to the emerging collective and personal identity related developmental assets of those Iraqi youth. This finding is in line with previous studies concerning the serious negative effects of cumulative trauma on physical and mental health (Kira, Fawzi, \& Fawzi, 2012d; Fawzi, Kira, Fawzi, Mohamed, \& Fawzi, 2013; Kira, Omidy, 
\& Ashby, in Press; Martin, Cromer, DePrince, \& Freyd, 2013; Cloitre, Stolbach, Herman, der Kolk, Pynoos, \& Wang; 2009). This also may validate the DBTF assumption about the centrality of the cumulative experience as opposed to the focus on single trauma.

Additionally, the effects of poverty on annihilation anxiety and other post-trauma spectrum disorders were significant, replicating previous studies. Childhood family poverty uniquely predicted PTSD, adult arrest, major depressive disorder, and poor academic achievement as well as physical health and life expectancy (e.g., Hudson, 2005; Kira et al., 2012a, 2013; Marmot, 2004; Nikulina, Widom, \& Czaja, 2011). Further, the intersectionality of the four types of systemic traumas that have similar marginalizing characteristics create cross-amplification processes that contribute to the severity of their consequences (e.g., Seng, Lopez, Sperlich, Hamama, \& Reed Meldrum, 2012).

It is worth noting that chronic (non-traumatic stress) was highly correlated with chronic traumatic stress and was as predictive of symptomatology. Multi-systemic chronic traumatic stress by definition can include microaggression (chronic quasi-traumatic) and macro-aggression (for example hate crimes, violent violations and direct threats) which are severe chronic traumatic stressors. This finding highlights the importance of the DBTF integrative theory of stress as it includes all traumatic and non-traumatic, chronic and non-chronic stressors that have a probability of contributing to physical and mental health symptoms.

Utilizing the developmentally-based trauma framework allows us to understand the negative developmental impact of such socialidentity and interdependence-based systemic traumas in adolescents' development. The serious mental health effects of such interdependence-based systemic trauma may be more obvious in the adolescence age when identity starts to emerge and adolescents begin to develop interdependence skills that further mature in adulthood. Moreover, a previous study of a large sample $(\mathrm{N}=501)$ of Iraqi refugees (adults), using the same framework and measures, found similar results (Kira et al., 2010b).

The results of the current research may apply to other Muslims, adolescents and adults in the US who are exposed to such backlash (Abu-Ras \& Suarez, 2009). The severity of the mental health impact of such continuous multi-systemic traumas on Iraqi refugees and Muslim Americans calls for parallel multi-systemic, multi-component, multi-modal approaches to treatment that are different from single trauma focused treatments (Kira, 2010b). Kira (2013), Kira et al. (2013) (see also: Murray, Cohen, \& Mannarino, 2103; Hobfoll et al., 2007) proposed an intervention strategy that modifies past-trauma focused interventions to fit the continuous and present trauma of discrimination. The proposed model includes six components: psycho-education of the present ongoing trauma and its proliferation and stress generation and accumulation dynamics, addressing safety and ongoing threats by behavior skills training (e.g., problem solving, assertiveness, anger management and emotion regulation), identity work and identity integration and social inclusion, stimulating a will to survive and related effective coping strategies such as stereotype rejection, inoculation against stress proliferation and accumulation dynamics inherent in such continuous traumas, and advocacy. There is recent strong empirical evidence of the effectiveness of present-focused (as contrasted by past-trauma focused) interventions (e.g. Classen et al., 2011). A recent study found that social re-inclusion can ameliorate and potentially reverse the negative effects of exclusion (Tang \& Richardson, 2013). Further, there is a need for policy makers, institutions and media to realize the results of such unfortunate policies of exclusions. Such communities have suffered enough due to oppression and discrimination, and some have been tortured before seeking refuge to the USA (e.g., Kira et al., 2006).

Conclusions: The emerging DBTF integrative paradigm has systematic, well-defined consistent theoretical structures that are based on development theories and have good empirical validity and utility. DBTF has attracted significant interest and is beginning to accumulate research support. One of the contributions of DBTF is the inclusion of multi-systemic trauma that is perpetrated and orchestrated by different dominant social systems that betrayed the individuals' sense of belonging, interdependence, attachment, fairness and trust. Each system has a differential negative impact on the individuals' health and wellbeing. The overall impact of multi-systemic traumas, such as Japanese internment, and backlash against Muslim Americans, is severe.

Limitations of study:

The current paper investigates empirically the relationship between several variables using a cross-sectional approach. The research points to only relationships and predictions. Cross-sectional studies can draw only probabilistic conclusions from the results. Unobserved confounding variables can distort statistical inference. Further, using snowballing sampling in the study limits the generalizability of the results. Additionally, studies on the group level may mask the individual differences in resiliency and vulnerability responding to such systemic traumas. Moreover, the empirical study did not test all the variables included in the theory discussed in the 
introduction (for example the cognitive, physiological, biological and neurological in addition to physical health variables, as well as the role of developmental assets, especially collective developmental assets in coping with such multi-systemic trauma). The study may be considered only as a partial validation of the basic premises of systemic trauma theory. Future studies should use a longitudinal or controlled approach, if possible, and larger representative samples. Replication studies are needed in addition to research examining other variables not tested in this study. Nevertheless, the findings provide evidence of an association between BT (as an identity multi-systemic type III ongoing trauma) and PTSD, CTD, and adolescents' internalizing and externalizing disorders. The present results provide initial evidence of the utility and validity of the DBTF trauma framework.

\section{References}

Abdulrahim, S., James, S. A., Yamout, R., \& Baker, W. (2012). Discrimination and Psychological Distress: Does Whiteness Matter for Arab Americans? Social Science \& Medicine, 75, 2116-2123. http://dx.doi.org/10.1016/j.socscimed.2012.07.030

Abu-Ras, W. M., \& Suarez, Z. E. (2009). Muslim Men and Women’s Perception of Discrimination, Hate Crimes, and PTSD Symptoms Post 9/11. Traumatology, 15, 48-63. http://dx.doi.org/10.1177/1534765609342281

Amer, M. M., \& Bagasra, A. (2013). Psychological Research with Muslim Americans in the Age of Islamophobia: Trends, Challenges, and Recommendations. American Psychologist, 68, 134-144. http://dx.doi.org/10.1037/a0032167

Aldwin, C. M. (1994). Stress, Coping, and Development. New York: The Guilford Press.

Altshuler, B. (1981). Modeling of Dose-Response Relationships. Environmental Health Perspectives, 42, $23-27$. http://dx.doi.org/10.1289/ehp.814223

Anestis, M. D., Pennings, S. M., Lavender, J. M., Tull, M. T., \& Gratz, K. L. (2013). Low Distress Tolerance as an Indirect Risk Factor for Suicidal Behavior: Considering the Explanatory Role of Non-Suicidal Self-Injury. Comprehensive Psychiatry, 54, 996-1002.

Aron, A., Aron, E. N., \& Smollan, D. (1992). Inclusion of Other in the Self Scale and the Structure of Interpersonal Closeness. Journal of Personality and Social Psychology, 63, 596-612. http://dx.doi.org/10.1037/0022-3514.63.4.596

Baltes, P. B. (1987). Theoretical Propositions of Lifespan Developmental Psychology: On the Dynamics between Growth and Decline. Developmental Psychology, 23, 611-626. http://dx.doi.org/10.1037/0012-1649.23.5.611

Baumeister, R. F., \& Leary, M. R. (1995). The Need to Belong: Desire for Interpersonal Attachments as a Fundamental Human Motivation. Psychological Bulletin, 117, 497-529. http://dx.doi.org/10.1037/0033-2909.117.3.497

Baumeister, R. F., Twenge, J. M., \& Nuss, C. K. (2002). Effects of Social Exclusion on Cognitive Processes: Anticipated Aloneness Reduces Intelligent Thought. Journal of Personality and Social Psychology, 83, 817-827. http://dx.doi.org/10.1037/0022-3514.83.4.817

Beer, R. (1995). A Dynamical Systems Perspective on Agent-Environment Interaction. Artificial Intelligence, 72, $173-215$. http://dx.doi.org/10.1016/0004-3702(94)00005-L

Begen, F., \& Turner-Cobb, J. (2012). The Need to Belong and Symptoms of Acute Physical Health in Early Adolescence. Journal of Health Psychology, 17, 907-916. http://dx.doi.org/10.1177/1359105311431176

Berreman, G. D. (1972). Race, Caste, and Other Invidious Distinctions in Social Stratification. Berkeley, CA: University of California.

Betemps, E. J., Smith, R. M., Baker, D. G., \& Rounds-Kugler, B. A. (2003). Measurement Precision of the Clinician Administered PTSD Scale (CAPS): A RASCH Model Analysis. Journal of Applied Measurement, 4, 59-69.

Blake, D. D., Weathers, F. W., Nagy, L. M., Kaloupek, D. G., Klauminzer, G., Charney, D. S., \& Keane, T. M. (1990). A Clinician Rating Scale for Assessing Current and Lifetime PTSD: The CAPS-1. The Behavior Therapist, 13, 187-188.

Bonanno, R. A., \& Hymel, S. (2013). Cyber Bullying and Internalizing Difficulties: Above and Beyond the Impact of Traditional Forms of Bullying. Journal of Youth and Adolescence, 42, 685-697. http://dx.doi.org/10.1007/s10964-013-9937-1

Bowlby, J. (1973). Separation: Anger and Anxiety. Attachment and Loss, Vol. 2. London: Hogarth.

Bourdieu, P., \& Passeron, J. C. (1990). Reproduction in Education, Society and Culture (2nd ed.). London: Sage.

Brendgen, M., Wanner, B., Morin, A. J. S., \& Vitaro, F. (2005). Relations with Parents with Peers, Temperament, and Trajectories of Depressed Mood during Early Adolescence. Journal of Abnormal Child Psychology, 33, 579-594. http://dx.doi.org/10.1007/s10802-005-6739-2

Bronstein, I., \& Montgomery, P. (2011). Psychological Distress in Refugee Children: A Systematic Review. Clinical Child and Family Psychology Review, 14, 44-56. http://dx.doi.org/10.1007/s10567-010-0081-0 
Brown, R. C., Berenz, E. C., Aggen, S. H., Gardner, C. O., Knudsen, G. P., Reichborn-Kjennerud, T., Kendler, K. S., \& Amstadter, A. B. (2013). Trauma Exposure and Axis I Psychopathology: A Cotwin Control Analysis in Norwegian Young Adults. Psychological Trauma: Theory, Research, Practice, and Policy. http://dx.doi.org/10.1037/a0034326

Cacioppo, J. T., \& Patrick, B. (2008). Loneliness: Human Nature and the Need for Social Connection. New York: W. W. Norton \& Company.

Canetti, D., Galea, S., Hall, B. J., Johnson, R. J., Palmieri, P. A., \& Hob-Foll, S. E. (2010). Exposure to Prolonged Socio-Political Conflict and the Risk of PTSD and Depression among Palestinians. Psychiatry, 73, 219-231. http://dx.doi.org/10.1521/psyc.2010.73.3.219

Capron, D. W., Norr, A. M., Macatee, R. J., \& Schmidt, N. B. (2013). Distress Tolerance and Anxiety Sensitivity Cognitive Concerns: Testing the Incremental Contributions of Affect Dysregulation Constructs on Suicidal Ideation and Suicide Attempt. Behavior Therapy, 44, 349-358. http://dx.doi.org/10.1016/j.beth.2012.12.002

Carolissen, R. (2012). "Belonging” as a Theoretical Framework for the Study of Psychology and Globalization. Journal of Social Issues, 68, 630-642. http://dx.doi.org/10.1111/j.1540-4560.2012.01767.x

Cassiman, S. A. (2005). Toward More Inclusive Poverty Knowledge: Traumatological Contributions to the Poverty Discourse. [Co-Published Simultaneously in the Social Policy Journal] Cutting Edge of Social Policy Research, 4, 93-106.

Catalano, R., Snowden, L., Shumway, M., \& Kessell, E. (2007). Unemployment and Civil Commitment: A Test of the Intolerance Hypothesis. Aggressive Behavior, 33, 272-280. http://dx.doi.org/10.1002/ab.20188

Chu, P. S., Saucier, D. A., \& Hafner, E. (2010). Meta-Analysis of the Relationships between Social Support and Well-Being in Children and Adolescents. Journal of Social \& Clinical Psychology, 29, 624-645. http://dx.doi.org/10.1521/jscp.2010.29.6.624

Classen, C., Cavanaugh, C., Kaupp, J., Aggarwal, R., Palesh, O., Koopman, C., Kraemer, H., \& Spiegel, D. (2011). A Comparison of Trauma-Focused and Present-Focused Group Therapy for Survivors of Childhood Sexual Abuse: A Randomized Controlled Trial. Psychological Trauma: Theory, Research, Practice and Policy, 3, 84-93. http://dx.doi.org/10.1037/a0020096

Cloitre, M., Stolbach, B. C., Herman, J. L., van der Kolk, B., Pynoos, R., \& Wang, J. (2009). A Developmental Approach to Complex PTSD: Childhood and Adult Cumulative Trauma as Predictors of Symptom Complexity. Journal of Traumatic Stress, 22, 399-408. http://dx.doi.org/10.1002/jts.20444

Cornil, Y., \& Chandon, P. (2013). From Fan to Fat? Vicarious Losing Increases Unhealthy Eating, but Self-Affirmation Is an Effective Remedy. Psychological Science, 24, 1936-1946. http://dx.doi.org/10.1177/0956797613481232

Cyr, K., Clément, M., \& Chamberland, C. (2103). Lifetime Prevalence of Multiple Victimizations and Its Impact on Children’s Mental Health. Journal of Interpersonal Violence, 29, 616-634.

Cummings, J. R., Bornovalova, M. A., Ojanen, T., Hunt, E., MacPherson, L., \& Lejuez, C. (2013). Time Doesn’t Change Everything: The Longitudinal Course of Distress Tolerance and Its Relationship with Externalizing and Internalizing Symptoms during Early Adolescence. Journal of Abnormal Child Psychology, 41, 735-748. http://dx.doi.org/10.1007/s10802-012-9704-x

Daly, M. C., Duncan, G. J., Kaplan, G. A., \& Lynch, J. W. (1998). Macro-to-Micro Links in the Relation between Income Inequality and Mortality. The Milbank Quarterly, 76, 315-339. http://dx.doi.org/10.1111/1468-0009.00094

Daniels, R., Taylor, S., \& Kitano, H. (1991). Japanese Americans from Relocation to Redress. Seattle, WA: University of Washington Press.

De Silva, M. J., McKenzie, K., Harpham, T., \& Huttly, S. R. (2005). Social Capital and Mental Illness: A Systematic Review. Journal of Epidemiology and Community Health, 59, 619-627. http://dx.doi.org/10.1136/jech.2004.029678

Dishion, T. J., Nelson, S. E., \& Yasui, M. (2005). Predicting Early Adolescent Gang Involvement from Middle School Adaptation. Journal of Clinical Child and Adolescent Psychology, 34, 62-73. http://dx.doi.org/10.1207/s15374424jccp3401_6

Dubow, E. F., Boxer, P., Huesmann, L. R., Landau, S., Dvir, S., Shikaki, K., \& Ginges, J. (2012). Cumulative Effects of Exposure to Violence on Posttraumatic Stress in Palestinian and Israeli Youth. Journal of Clinical Child \& Adolescent Psychology, 41, 837-844. http://dx.doi.org/10.1080/15374416.2012.675571

Elhai, J. D., Lindsay, B. M., Gray, M. J., Grubaugh, A. L., North, T. C., \& Frueh, B. C. (2006). Examining the Uniqueness of Frequency and Intensity Symptom Ratings in Posttraumatic Stress Disorder Assessment. Journal of Nervous and Mental Disease, 194, 940-944. http://dx.doi.org/10.1097/01.nmd.0000243011.76105.4b

Erikson, E. H. (1968). Identity: Youth and Crisis. New York: Norton.

Fawzi, M. H., Kira, I. A., Fawzi Jr., M. M., Mohamed, H. E., \& Fawzi, M. M. (2013). Trauma Profile in Egyptian Adolescents with First Episode Schizophrenia: Relation to Psychopathology and Plasma BDNF. Journal of Nervous and Mental Disease, 201, 23-29. http://dx.doi.org/10.1097/NMD.0b013e31827ab268

Figley, C. R. (1995). Compassion Fatigue: Coping with Secondary Traumatic Stress Disorder in Those Who Treat the Traumatized. 
New York: Brunner/Mazel.

Freyd, J. (1996). Betrayal Trauma: The Logic of Forgetting Child Abuse. Cambridge, MA: Harvard University Press.

Freyd, J. J., DePrince, A. P., \& Gleaves, D. (2007). The State of Betrayal Trauma Theory: Reply to McNally-Conceptual Issues and Future Directions. Memory, 15, 295-311. http://dx.doi.org/10.1080/09658210701256514

Figley, C. R. (1995). Compassion Fatigue: Toward a New Understanding of the Costs of Caring. In B. H. Stamm (Ed.), Secondary Traumatic Stress: Self-Care Issues for Clinicians, Researchers, and Educators (pp. 3-28). Lutherville, MD: Sidran.

Gerber, J., \& Wheeler, L. (2009). On Being Rejected: A Meta-Analysis of Experimental Research on Rejection. Perspectives on Psychological Science, 4, 468-488. http://dx.doi.org/10.1111/j.1745-6924.2009.01158.x

Gilbert, K. L. (2010). A Meta-Analysis of Social Capital and Health. Dissertation Abstracts International: Section B. The Sciences and Engineering, 70, 6142.

Greene, M. L., Way, N., \& Pahl, K. (2006). Trajectories of Perceived Adult and Peer Discrimination among Black, Latino, and Asian American Adolescents: Patterns and Psychological Correlates. Developmental Psychology, 42, 218-236. http://dx.doi.org/10.1037/0012-1649.42.2.218

Haber, M. G., Cohen, J. L., Lucas, T., \& Baltes, B. B. (2007). The Relationship between Self-Reported Received and Perceived Social Support: A Meta-Analytic Review. American Journal of Community Psychology, 39, 133-144. http://dx.doi.org/10.1007/s10464-007-9100-9

Herman, J. L. (1992). Trauma and Recovery. New York: Basic Books.

Hermans, H. J. M., \& Dimaggio, G. (2007). Self, Identity, and Globalization in Times of Uncertainty: A Dialogical Analysis. Review of General Psychology, 11, 31-61. http://dx.doi.org/10.1037/1089-2680.11.1.31

Holt-Lunstad, J., Smith, T. B., \& Layton, J. B. (2010). Social Relationships and Mortality Risk: A Meta-Analytic Review. PLoS Medicine, 7, Article ID: e1000316. http://dx.doi.org/10.1371/journal.pmed.1000316

Holtz, T. H. (1998). Refugee Trauma versus Torture Trauma: A Retrospective Controlled Cohort Study of Tibetan Refugees. Journal of Nervous and Mental Disease, 186, 24-34. http://dx.doi.org/10.1097/00005053-199801000-00005

Hobfoll, S. E. (2002). Social and Psychological Resources and Adaptation. Review of General Psychology, 6, 307-324. http://dx.doi.org/10.1037/1089-2680.6.4.307

Hobfoll, S. E., Watson, P., Bell, C., Bryant, R., Brymer, M., Friedman, M. J. et al. (2007). Five Essential Elements of Immediate and Mid-Term Mass Trauma Intervention: Empirical Evidence. Psychiatry: Interpersonal and Biological Processes, 70, 283-315. http://dx.doi.org/10.1521/psyc.2007.70.4.283

Hudson, C. G. (2005). Socioeconomic Status and Mental Illness: Tests of the Social Causation and Selection Hypotheses. American Journal of Orthopsychiatry, 75, 3-18. http://dx.doi.org/10.1037/0002-9432.75.1.3

Huesmann, L. R., Dubow, E. F., Boxer, P., Souweidane, V., \& Ginges, J. (2012). Foreign Wars and Domestic Prejudice: How Media Exposure to the Israeli-Palestinian Conflict Predicts Ethnic Stereotyping by Jewish and Arab American Adolescents. Journal of Research on Adolescence, 22, 556-570. http://dx.doi.org/10.1111/j.1532-7795.2012.00785.x

Hurvich, M. (2003). The Place of Annihilation Anxieties in Psychoanalytic Theory. Journal of the American Psychoanalytic Association, 51, 579-616. http://dx.doi.org/10.1177/00030651030510020801

Hurvich, M. (1989). Traumatic Moment, Basic Dangers, and Annihilation Anxiety. Psychoanalytic Psychology, 6, $309-323$. http://dx.doi.org/10.1037/h0079740

Jensen, L. A., Arnett, J. J., \& McKenzie, J. (2011). Globalization and Cultural Identity. In S. J. Schwartz, K. Luyckx, \& V. L. Vignoles (Eds.), Handbook of Identity Theory and Research (pp. 285-304). New York: Springer Publishing Company.

Kadushin, C. (2012). Understanding Social Networks: Theories, Concepts, and Findings. Oxford: Oxford University Press.

Karam, E. G., Friedman, M. J., Hill, E. D., Kessler, R. C., McLaughlin, K. A., Petukhova, M., Sampson, L., Shahly, V., Angermeyer, M. C., Bromet, E. J., de Girolamo, G., de Graaf, R., Demyttenaere, K., Ferry, F., Florescu, S. E., Haro, J. M., He, Y., Karam, A. N., Kawakami, N., Kovess-Masfety, V., Medina-Mora, M. E., Browne, M. A. O., Posada-Villa, J. A., Shalev, A. Y., Stein, D. J., Viana, M. C., Zarkov, Z., \& Koenen, K. C. (2013). Cumulative Traumas and Risk Thresholds: $12-$ Month PTSD in the Wrold Mental Health(WMH) Surveys. Depression and Anxiety, 31, 130-142.

Kim, Y. S., \& Leventhal, B. (2008). Bullying and Suicide. A Review. International Journal of Adolescent Medicine and Health, 20, 133-154. http://dx.doi.org/10.1515/IJAMH.2008.20.2.133

Kira, I. (2013). Interventions with Continuous Traumatic Stress of Discrimination in Youth. The International Symposium on Arab Youth: Developmental Pathways for Identity. Windsor: University of Windsor. http://scholar.uwindsor.ca/arabyouthsymp/conference presentations/presentations2/3/

Kira, I. (2010). Etiology and Treatments of Post-Cumulative Traumatic Stress Disorders in Different Cultures. Traumatology: An International Journal, 16, 128-141.

Kira, I. (2004). Secondary Trauma in Treating Refugee Survivors of Torture and Their Families. Torture, 14, 38-44. 
Kira, I. (2001). Taxonomy of Trauma and Trauma Assessment. Traumatology, 2, 1-14.

Kira, I. A., Omidy, A. Z., \& Ashby, J. S. (in Press). Cumulative Trauma, Appraisal and Coping in Palestinian and American Indian Adults: Two Cross-Cultural Studies. Traumatology: An International Journal.

Kira, I., Amer, M. M., \& Wrobel, N. H. (2014). Arab Refugees: Trauma, Resilience, and Recovery. In S. C. Nassar-McMillan et al. (Eds.), A Biopsychosocial Approach to Arab Americans: Perspectives on Culture, Development, and Health (pp. 175-195). New York: Springer. http://dx.doi.org/10.1007/978-1-4614-8238-3 9

Kira, I., Ashby, J. S., Lewandowski, L., Alawneh, A. N., Mohanesh, J., \& Odenat, L. (2013). Advances in Continuous Traumatic Stress Theory: Traumatogenic Dynamics and Consequences of Intergroup Conflict: The Palestinian Adolescents Case. Psychology, 4, 396-409. http://dx.doi.org/10.4236/psych.2013.44057

Kira, I., Templin, T., Lewandowski, L., Ramaswamy, V., Bulent, O., Mohanesh, J., \& Abdulkhaleq, H. (2012a). Collective and Personal Annihilation Anxiety: Measuring Annihilation Anxiety AA. Psychology, 3, 90-99. http://dx.doi.org/10.4236/psych.2012.31015

Kira, I., Templin, T., Lewandowski, L., \& Ashby, J. (2012b). Cumulative Trauma Disorder Scale: Two Studies. Psychology, 3, 643-656. http://dx.doi.org/10.4236/psych.2012.39099

Kira, I., Ashby, J., Lewandowski, L., Smith, I., \& Odenat, L. (2012c). Gender Inequality and Its Effects in Females Torture Survivors. Psychology, 3, 352-363. http://dx.doi.org/10.4236/psych.2012.34050

Kira, I., Fawzi, M., \& Fawzi, M. (2012d). The Dynamics of Cumulative Trauma and Trauma Types in Adults Patients with Psychiatric Disorders: Two Cross-Cultural Studies. Traumatology: An International Journal, 19, 179-195.

Kira, I., Lewandowski, L., Somers, C., Yoon, J., \& Chiodo, L. (2012e). The Effects of Trauma Types, Cumulative Trauma, and PTSD on IQ in Two Highly Traumatized Adolescent Groups. Psychological Trauma: Theory, Research, Practice, and Policy, 4, 128-139. http://dx.doi.org/10.1037/a0022121

Kira, I., Templin, T., Lewandowski, L., Ramaswamy, V., Bulent, O., Abu-Mediene, S., Mohanesh, J., \& Alamia, H. (2011). Cumulative Tertiary Appraisal of Traumatic Events across Cultures: Two Studies. Journal of Loss and Trauma: International Perspectives on Stress \& Coping, 16, 43-66. http://dx.doi.org/10.1080/15325024.2010.519288

Kira, I., Smith, I., Lewandowski, L., \& Templin, T. (2010a). The Effects of Perceived Gender Discrimination on Refugee Torture Survivors: A Cross-Cultural Traumatology Perspective. Journal of the American Psychiatric Nurses Association, 16, 299-306. http://dx.doi.org/10.1177/1078390310384401

Kira, I., Lewandowsi, L., Templin, T., Ramaswamy, V., Ozkan, B., \& Mohanesh, J. (2010b). The Effects of Perceived Discrimination and Backlash on Iraqi Refugees' Mental and Physical Health. Journal of Muslim Mental Health, 5, 59-81. http://dx.doi.org/10.1080/15564901003622110

Kira, I., Lewandowsk, L., Templin, T., Ramaswamy, V., Ozkan, B., \& Mohanesh, J. (2008a). Measuring Cumulative Trauma Dose, Types and Profiles Using a Development-Based Taxonomy of Trauma. Traumatology: An International Journal, 14, 62-87.

Kira, I., Templin, T., Lewandowsk, L., Ramaswamy, V., Ozkan, B., \& Mohanesh, J. (2008b). The Physical and Mental Health Effects of Iraq War Media Exposure on Iraqi Refugees. Journal of Muslim Mental Health, 3, 193-215. http://dx.doi.org/10.1080/15564900802487592

Kira, I., Hammad, A., Lewandowski, L., Templin, T., Ramswamy, V., Ozkan, B., \& Mohanesh, J. (2007). The Health and Mental Status of Iraqi Refugees and Their Etiology. Ethnicity \& Disease, 17, 79-82.

Kira, I., Templin, T., Lewandowski, L., Clifford, D., Wiencek, E., Hammad, A., Al-Haidar, A., \& Mohanesh, J. (2006). The Effects of Torture: Two Community Studies. Peace and Conflict: Journal of Peace Psychology, 12, 205-228. http://dx.doi.org/10.1207/s15327949pac1203_1

Klarić, M., Kvesić, A., Mandić, V., Petrov, B., \& Frančišković, T. (2013). Secondary Traumatisation and Systemic Traumatic Stress. Psychiatria Danubina, 25, 29-36.

Kloep, M. (1999). Love Is All You Need? Focusing on Adolescents’ Life Concerns from an Ecological Point of View. Journal of Adolescence, 22, 49-63. http://dx.doi.org/10.1006/jado.1998.0200

Laird, R. D., Jordan, K. Y., Dodge, K. A., Pettit, G. S., \& Bates, J. E.(2001). Peer Rejection in Childhood, Involvement with Antisocial Peers in Early Adolescence, and the Development of Externalizing Behavior Problems. Development and Psychopathology, 13, 337-354. http://dx.doi.org/10.1017/S0954579401002085

Leary, M. R. (2005). Sociometer Theory and Pursuit of Relational Value: Getting to the Root of Self-Esteem. European Review of Social Psychology, 16, 75-111. http://dx.doi.org/10.1080/10463280540000007

Leary, M. R., Kowalski, R. M., Smith, L., \& Phillips, S. (2003). Teasing, Rejection, and Violence: Case Studies of the School Shootings. Aggressive Behavior, 29, 202-214. http://dx.doi.org/10.1002/ab.10061

Leary, M. R., Tipsord, J. M., \& Tate, E. B. (2008). Allo-Inclusive Identity: Incorporating the Social and Natural Worlds into One's Sense of Self. In H. Wayment, \& J. Bauer (Eds.), Transcending Self-Interest: Psychological Explorations of the 
Quiet Ego (pp. 137-147). Washington DC: American Psychological Association. http://dx.doi.org/10.1037/11771-013

Loo, C. M., Fairbank, J. A., Scurfield, R. M., Ruch, L. O., King, D. W., Adams, L. J. et al. (2001). Measuring Exposure to Racism: Development and Validation of a Race-Related Stressor Scale (RRSS) for Asian American Vietnam Veterans. Psychological Assessment, 13, 503-520. http://dx.doi.org/10.1037/1040-3590.13.4.503

Malone, G. P., Pillow, D. R., \& Osman, A. (2011). The General Belongingness Scale (GBS): Assessing Achieved Belongingness. Personality and Individual Differences, 52, 311-316. http://dx.doi.org/10.1016/j.paid.2011.10.027

Major, B., Mendes, W. B., \& Dovidio, J. F. (2013). Intergroup Relations and Health Disparities: A Social Psychological Perspective. Health Psychology, 32, 514-524. http://dx.doi.org/10.1037/a0030358

Marmot, M. (2004). Status Syndrome. How Your Social Standing Directly Affects Your Health and Life Expectancy. London: Bloomsbury.

Martin, C. G., Cromer, L. D., DePrince, A. P., \& Freyd, J. J. (2013). The Role of Cumulative Trauma, Betrayal, and Appraisals in Understanding Trauma Symptomatology. Psychological Trauma: Theory, Research, Practice, and Policy, 5, 110-118. http://dx.doi.org/10.1037/a0025686

Maslow, A. H. (1987). Motivation and Personality (3rd ed., revised by R. Frager, J. Fadiman, C. McReynolds, \& R. Cox), New York: Harper \& Row.

Moradi, B., \& Hasan, N. T. (2004). Arab American Persons' Reported Experiences of Discrimination and Mental Health: The Mediating Role of Personal Control. Journal of Counseling Psychology, 51, 418-428. http://dx.doi.org/10.1037/0022-0167.51.4.418

Murayama, H., Fujiwara, Y., \& Kawachi, I. (2012). Social Capital and Health: A Review of Prospective Multilevel Studies. Journal of Epidemiology, 22, 179-187.

Murphy, M. L. M., Slavich, G. M., Rohleder, N., \& Miller, G. (2013). Targeted Rejection Triggers Differential Pro- and AntiInflammatory Gene Expression in Adolescents as a Function of Social Status. Clinical Psychological Science, 1, 30-40.

Murray, L. K., Cohen, J. A., \& Mannarino, A. P. (2013). Trauma-Focused Cognitive Behavioral Therapy for Youth Who Experience Continuous Traumatic Exposure. Peace and Conflict: Journal of Peace Psychology, 19, 180-195. http://dx.doi.org/10.1037/a0032533

Neria, Y., \& Sullivan, G. (2011). Understanding the Mental Health Effects of Indirect Exposure to Mass Trauma through the Media. Journal of the American Medical Association, 306, 1374-1375. http://dx.doi.org/10.1001/jama.2011.1358

Nickerson, A., Bryant, R. A., Brooks, R., Steel, Z., \& Silove, D. (2009). Fear of Cultural Extinction and Psychopathology among Mandaean Refugees: An Exploratory Path Analysis. CNS Neuroscience and Therapeutics, 15, 227-236. http://dx.doi.org/10.1111/j.1755-5949.2009.00094.x

Nikulina, N., Widom, C. S., \& Czaja, S. (2011). The Role of Childhood Neglect and Childhood Poverty in Predicting Mental Health, Academic Achievement, and Crime in Adulthood. American Journal of Community Psychology, 48, 309-321. http://dx.doi.org/10.1007/s10464-010-9385-y

Nyqvist, F., Pape, B., Pellfolk, T., Forsman, A. K., \& Wahlbeck, K. (2013). Structural and Cognitive Aspects of Social Capital and All-Cause Mortality: A Meta-Analysis of Cohort Studies. Social Indicators Research. http://dx.doi.org/10.1007/s11205-013-0288-9

O’Brien, R. M. (2007). A Caution Regarding Rules of Thumb for Variance Inflation Factors. Quality \& Quantity, 41, 673690. http://dx.doi.org/10.1007/s11135-006-9018-6

Padela, A. I., \& Heisler, M. (2010). The Association of Perceived Abuse and Discrimination After September 11, 2001, with Psychological Distress, Level of Happiness, and Health Status among Arab Americans. American Journal of Public Health, 100, 284-291. http://dx.doi.org/10.2105/AJPH.2009.164954

Palmieri, P., Weathers, F., Difede, J., \& King, D. (2007). Confirmatory Factor Analysis of the PTSD Checklist and the ClinicianAdministered PTSD Scale in Disaster Workers Exposed to the World Trade Center Ground Zero. Journal of Abnormal Psychology, 116, 329-341. http://dx.doi.org/10.1037/0021-843X.116.2.329

Pearlin, L. I., Aneshensel, C. S., \& Leblanc, A. J. (1997). The Forms and Mechanisms of Stress Proliferation: The Case of AIDS Caregivers. Journal of Health and Social Behavior, 38, 223-236. http://dx.doi.org/10.2307/2955368

Petot, J. (1976). Anxiety and Existence. Perspectives Psychiatriques, 56, 97-109.

Platt, M., Barton, J., \& Freyd, J. J. (2009). A Betrayal Trauma Perspective on Domestic Violence. In E. Stark, \& E. S. Buzawa (Eds.), Violence against Women in Families and Relationships (Vol. 1, pp. 185-207). Westport, CT: Greenwood Press.

Poortinga, W. (2006). Social Capital: An Individual or Collective Resource for Health? Social Science and Medicine, 62, 292302. http://dx.doi.org/10.1016/j.socscimed.2005.06.008

Prati, G., \& Pietrantoni, L. (2009). Optimism, Social Support, and Coping Strategies as Factors Contributing to Posttraumatic Growth: A Meta-Analysis. Journal of Loss and Trauma, 14, 364-388. http://dx.doi.org/10.1080/15325020902724271 
Reijntjes, A., Thomaes, S., Bushman, B. J., Boelen, P. A., de Castro, B. O., \& Telch, M. J. (2010). The Outcast-Lash-Out Effect in Youth: Alienation Increases Aggression Following Peer Rejection. Psychological Science, 21, 1394-1398. http://dx.doi.org/10.1177/0956797610381509

Reynolds, W. M. (2000). Adolescent Psychopathology Scale-Short Form: Professional Manual. Odessa, FL: Psychological Assessment Recourses.

Roberts, L. D., Indermaur, D., \& Spiranovic, C. (2013). Fear of Cyber-Identity Theft and Related Fraudulent Activity. Psychiatry, Psychology, \& Law, 20, 315-328. http://dx.doi.org/10.1080/13218719.2012.672275

Rosenfeld, R. (2009). Crime Is the Problem: Homicide, Acquisitive Crime, and Economic Conditions. Journal of Quantitative Criminology, 25, 287-306. http://dx.doi.org/10.1007/s10940-009-9067-9

Rousseau, C., Hassan, G., \& Moreau, N. (2011). Perceived Discrimination and Its Association with Psychological Distress among Newly Arrived Immigrants before and after September 11, 2001. American Journal of Public Health, 101, 909-915. http://dx.doi.org/10.2105/AJPH.2009.173062

Sack, W. H., Him, C., \& Dickason, D. (1999). Twelve-Year Follow-Up Study of Khmer Youths Who Suffered Massive War Trauma as Children. Journal of the American Academy of Child and Adolescent Psychiatry, 38, 1173-1179. http://dx.doi.org/10.1097/00004583-199909000-00023

Sandstrom, M. J. (2004). Pitfalls of the Peer World: How Children Cope with Common Rejection Experiences. Journal of Abnormal Child Psychology, 32, 67-81. http://dx.doi.org/10.1023/B:JACP.0000007581.95080.8b

Schmitt, M. T., \& Branscombe, N. R. (2002). The Meaning and Consequences of Perceived Discrimination in Disadvantaged and Privileged Social Groups. In W. Stroebe, \& M. Hewstone (Eds.), European Review of Social Psychology (Vol. 12, pp. 167-199). Chichester: Wiley.

Seng, J. S., Lopez, W. D., Sperlich, M. A., Hamama, L., \& Reed Meldrum, C. D. (2012). Marginalized Identities, Discrimination Burden, and Mental Health: Empirical Exploration of an Interpersonal-Level Approach to Modeling Intersectionality. Social Science \& Medicine, 75, 2437-2445. http://dx.doi.org/10.1016/j.socscimed.2012.09.023

Sidanius, J., \& Pratto, F. (1999). Social Dominance: An Intergroup Theory of Social Hierarchy and Oppression. New York: Cambridge University Press. http://dx.doi.org/10.1017/CBO9781139175043

Silver, R. C., Holman, E. A., McIntosh, D. N., Poulin, M., Gil-Rivas, V., \& Pizarro, J. (2006). Coping with a National Trauma: A Nationwide Longitudinal Study of Responses to the Terrorists Attacks of September 11th. In Y. Neria, R. Gross, R. Marshall, \& E. Susser (Eds.), 9/11: Mental Health in the Wake of Terrorist Attacks (pp. 45-70). New York: Cambridge University Press.

Silver, R. C., Holman, E. A., Andersen, J. B., Poulin, M., McIntosh, D. N., \& Gil-Rivas, V. (2013). Mental- and PhysicalHealth Effects of Acute Exposure to Media Images of the September 11, 2001, Attacks and the Iraq War. Psychological Science, 24, 1623-1634.

Sirin, S. R., \& Fine, M. (2007). Hyphenated Selves: Muslim-American Youth Negotiating Their Identities across the Fault Lines of Global Conflict. Applied Developmental Science, 11, 151-163. http://dx.doi.org/10.1080/10888690701454658

Smith, H. J., Pettigrew, T. F., Pippin, G. M., \& Bialosiewicz, S. (2012). Relative Deprivation: A Theoretical and Meta-Analytic Review. Personality and Social Psychology Review, 16, 203-232. http://dx.doi.org/10.1177/1088868311430825

Speed, B. (1999). Individuals in Context and Contexts in Individuals. The Australian and New Zealand Journal of Family Therapy, 20, 131-138. http://dx.doi.org/10.1111/j.0814-723X.1999.00114.x

Spivey, M., \& Dale, R. (2006). Continuous Temporal Dynamics in Real-Time Cognition. Current Directions in Psychological Science, 15, 207-211. http://dx.doi.org/10.1111/j.1467-8721.2006.00437.x

Straker, G., \& The Sanctuaries Counseling Team (1987). The Continuous Traumatic Stress Syndrome: The Single Therapeutic Interview. Psychology in Society, 8, 46-79.

Tajfel, H., \& Turner, J. C. (1979). An Integrative Theory of Intergroup Conflict. In S. Worchel, \& W. G. Austin (Eds.), The Social Psychology of Intergroup Relations (pp. 33-47). Monterey, CA: Brooks/Cole.

Tang, H., \& Richardson, R. (2013). Reversing the Negative Psychological Sequelae of Exclusion: Inclusion Is Ameliorative but Not Protective against the Aversive Consequences of Exclusion. Emotion, 13, 139-150. http://dx.doi.org/10.1037/a0029521

Terr, L. C. (1991). Childhood Traumas: An Outline and Overview. American Journal of Psychiatry, 148, 10-20.

Wann, D. L., Waddill, P. J., Polk, J., \& Weaver, S. (2011). The Team Identification-Social Psychological Health Model: Sport Fans Gaining Connections to Others via Sport Team Identification. Group Dynamics: Theory, Research, and Practice, 15, 75-89. http://dx.doi.org/10.1037/a0020780

Waugh, C. E., \& Fredrickson, B. L. (2006). Nice to Know You: Positive Emotions, Self-Other Overlap, and Complex Understanding in the Formation of a New Relationship. Journal of Positive Psychology, 1, 93-106. http://dx.doi.org/10.1080/17439760500510569 
Williams, K. D. (2009). Ostracism: A Temporal Need Threat Model. Advances in Experimental Social Psychology, 41, 275314. http://dx.doi.org/10.1016/S0065-2601(08)00406-1

Williams, D., \& Mohammed, S. (2009). Discrimination and Racial Disparities in Health: Evidence and Needed Research. Journal of Behavioral Medicine, 32, 20-47. http://dx.doi.org/10.1007/s10865-008-9185-0

Winnicott, D. (1974). The Fear of Breakdown. International Review of Psychoanalysis, 1, 103-107.

Wrzus, C., Hänel, M., Wagner, J., \& Neyer, F. J. (2013). Social Network Changes and Life Events across the Lifespan: A Meta-Analysis. Psychological Bulletin, 139, 53-80. http://dx.doi.org/10.1037/a0028601

van der Kolk, B. A. (2005). Developmental Trauma Disorder: Toward a Rational Diagnosis for Children with Complex Trauma Histories. Psychiatric Annals, 35, 401-408.

Zvolensky, M. J., Bernstein, A., \& Vujanovic, A. A. (2011). Distress Tolerance: Theory, Research, and Clinical Applications. New York: Guilford Press. 